\title{
Bis-Chalcone Derivatives Derived from Natural Products as Near- UV/Visible Light Sensitive Photoinitiators for 3D/4D Printing
}

Hong Chen ${ }^{1,2}$, Guillaume Noirbent ${ }^{3}$, Shaohui Liu ${ }^{1,2}$, Damien Brunel ${ }^{3}$, Bernadette Graff $^{1,2}$, Didier Gigmes ${ }^{3}$, Yijun Zhang ${ }^{1,2}$, Ke Sun ${ }^{1,2}$, Fabrice Morlet-Savary ${ }^{1,2}$, Pu Xiao $^{4 *}$, Frédéric Dumur ${ }^{3 *}$, Jacques Lalevée ${ }^{1,2^{*}}$

1 Institut de Science des Matériaux de Mulhouse, IS2M-UMR CNRS 7361, UHA, 15, rue Jean Starcky, Cedex 68057 Mulhouse, France ; jacques.lalevee@uha.fr

2 Université de Strasbourg, France; jacques.lalevee@uha.fr

3 Aix Marseille Univ, CNRS, ICR UMR 7273, F-13397 Marseille, France ; frederic.dumur@univ-amu.fr

4 Research School of Chemistry, Australian National University, Camberra, ACT 2601, Australia; pu.xiao@anu.edu.au

* Corresponding author: jacques.lalevee@uha.fr (J. L.), frederic.dumur@univ-amu.fr (F.D.); pu.xiao@anu.edu.au (P. X.).

Abstract: Four series of bis-chalcone compounds based on benzylpiperidinone, tetrahydrothiopyranone, pyridine or biphenyl central part were designed and synthesized, enabling to develop ten bis-chalcones varying both by the central cores but also by the substitution patterns (ortho, meta, para-positions) and the choice of the different groups attached to the peripheral substituents (alkoxy or allyloxy-substituted aromatic rings, thiophene, or ferrocene). In this series of ten bis-chalcones, eight of them were never synthesized before (i.e. only bis-chalcones 8 and 10 were already reported albeit never used as photoinitiators). These different dyes were proposed as new near-UV/visible light sensitive photoinitiators, in combination with an amine and an iodonium salt, to initiate the free radical photopolymerization (FRP) of PEGdiacrylate and the cationic photopolymerization (CP) of EPOX under LED@405nm and LED@375nm irradiation conditions. For the photopolymerization of acrylates carried out between thin films in laminate, all the bis-chalcones proposed in this work showed higher photoinitiation abilities upon irradiation with a LED at $375 \mathrm{~nm}$ than at $405 \mathrm{~nm}$, which were mainly due to their excellent light absorption properties in the 
near-UV region. Remarkably, in contrast with the other two series of bis-chalcone compounds, pyridine-based bis-chalcones proved to be the most efficient photoinitiators, especially the bis-chalcones 5 and 9. Furthermore, all of them could also promote the cationic polymerization of epoxides upon LED irradiation at $375 \mathrm{~nm}$, in the presence of an iodonium salt and an amine. More interestingly, some 3D patterns fabricated through the free radical polymerization of PEG-diacrylate demonstrated reversible swelling properties and shape-memory for the access to 4D printing.

Keywords: Bis-chalcones, photopolymerization, Reversible shape memory

\section{Introduction}

Photopolymerization is a process that rapidly transforms a liquid monomer into a solid material upon irradiation with light (e.g. ultraviolet light, visible light or even infrared) [1-6]. With the advantages of reacting rapidly at room temperature while requiring a minimum of energy to be initiated, of being a relatively low cost polymerization technique allowing a perfect temporal and spatial control [7-9], free radical photopolymerization is still of crucial interest in both the academic and the industrial communities. Due to the severe limitations such as oxygen inhibition and light attenuation existing during the polymerization process due to shielding effects [10], the development of new high-performance photoinitiating systems that can work under near UV and/or visible light region, in environmentally friendly conditions and that are the less possible toxic are highly desirable. Some compounds that derive from natural plants and notably the dyes that are responsible of the color of numerous flowers and vegetables are potential candidates for photoinitiation due to their highly conjugated structures which allow them to absorb over the visible range.

Due to their good biocompatibility and stability, photoinitiators derived from natural plants can be of great interest in various research fields ranging from imaging, radiation curing, and optics technologies to (bio)medicine, microelectronics, and material science [11-15]. After absorbing a light of appropriate wavelength, these compounds are promoted to an excited state that can interact with the additive through an electron (or energy) transfer reaction to produce reactive species (such as cations or free radicals) that can initiate the photopolymerization reaction [16-18]. However, light absorption properties of the chromophore are not the only parameter governing the 
reactivity of photoinitiators, and other parameters such as the rate constant of interaction of photoinitiators with the different additives introduced into the photocurable resins, the excited state lifetimes and energies, the redox potentials etc. are also important to govern the polymerization efficiency.

Chalcone is a class of dyes that can be found in many natural plants and exhibit different light absorption properties and colors depending on the substituents as well as their positions onto the chalcone backbone [19-22]. In our previous research, more than 50 mono-chalcone derivatives have been studied as photoinitiators for their excellent light absorption properties at the near UV and visible range [23-25]. Moreover, some of them exhibited high photopolymerization efficiencies for the free radical photopolymerization of acrylates upon irradiation with a LED@405nm. However, to the best of our knowledge, bis-chalcones have only been very scarcely studied in the literature as photoinitiators so that the mechanism involved in the photopolymerization process while using these bis-chalcone derivatives is still unclear [26]. More precisely, it would be very interesting and of great significance to explore the effects of different bis-chalcones structures on the photopolymerization of acrylate or epoxy monomers.

Furthermore, shape memory polymers (SMP) have the ability to recover its original shape from temporary shape after receiving appropriate stimulation [27], such as heating [28-29], light [30], electric field [31], magnetic field [32] or wet [33-34]. In recent years, SMP have gained increasing attention in medical applications such as smart sutures, tissue engineering stents and drug delivery [35-38].

Hence, in this work, four series of novel bis-chalcone compounds (Scheme 1) with a broad absorption extending over the near UV/visible range have been synthesized and examined for the first time as photoinitiators in combination with an amine and an iodonium salt for the free radical polymerization of acrylates and the cationic photopolymerization (CP) of EPOX in thin samples $(20 \mu \mathrm{m})$. To support the excellent performances of the different compounds as photoinitiators, photophysical properties of the ten bis-chalcone derivatives were studied, including steady state photolysis, fluorescence quenching, cyclic voltammetry as well as ESR experiments. Theoretical calculations were also carried out to design these different dyes to ensure their good light absorption properties. Photoinitiation abilities of the different dyes were monitored by Real-time Fourier Transform InfraRed (RT-FTIR) spectroscopy. 3D printing experiments were also carried out to evidence the interest of the new formulations. Finally, the ability of polymer films prepared with the newly proposed 
PISs with shape-shifting property was studied through swelling and dehydration induced actuation for the access to $4 \mathrm{D}$ printed materials i.e. change of shape and mechanical properties of $3 \mathrm{D}$ patterns through controlled hydration and thermal processes.

Piperidinone Based Bis-Chalcones<smiles>[R]C=C1CN(Cc2ccccc2)CC(=C[R])C1=O</smiles>

1. $\mathbf{R}=$

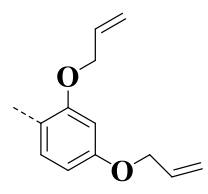

2. $\mathbf{R}=$

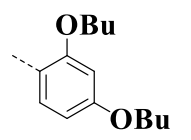

Tetrahydrothiopyranone Based Bis-Chalcones<smiles>[R]C=C1CSCC/C1=C\[R]</smiles>

Pyridines Based Bis-Chalcones<smiles>[R]C=CC(=O)c1cccc(C(=O)C=C[R])n1</smiles>

Biphenyl Based Bis-Chalcone

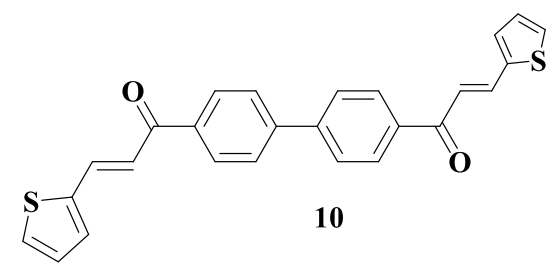

3. $\mathbf{R}=\quad \underset{\mathrm{Fe}}{\mathrm{Fe}}$

4. $R=$<smiles>CCOc1ccc(C)c(OC)c1</smiles>

5. $\mathbf{R}=$<smiles>CCOc1ccccc1</smiles>

6. $\mathbf{R}=$<smiles>C=CCOc1ccc(OCC=C)c(N(CC)CC)c1OCCC</smiles>

8. $\mathbf{R}=$

Q $\mathrm{Fe}$

9. $\mathbf{R}=$<smiles>COc1cccc(O)c1O</smiles>

Scheme 1. Chemical structures of bis-chalcones 1-10. 


\section{Materials and Methods}

\subsection{Material}

The ten bis-chalcones 1-10 used as photoinitiators were prepared as reported in the supporting information, and the molecular structures are given in the Scheme 1. The free radical photopolymerization monomer polyethylene glycol (600) diacrylate (PEGacrylate: SR 610) was obtained from Sartomer-Europe. 3,4-Epoxycyclohexylmethyl 3,4-epoxycyclohexanecarboxylate (commercially known as EPOX or Uvacure 1500) used as benchmark monomer for cationic photopolymerization was purchased from Allnex. Bis-(4-tert-butylphenyl) iodonium hexafluorophosphate (Iod, iodonium salt, commercially known as Speedcure 938) and ethyl 4-dimethylaminobenzoate (amine, commercially known as Speedcure EDB) were purchased from Lambson Ltd. (Wetherby, UK) and used as co-initiator and electron donor, respectively. Phenyl- $N$ tert-butylnitrone (PBN) was purchased from Sigma-Aldrich (St. Louis, MO, USA). Their corresponding chemical structures are presented in Scheme 2. The solvent (e.g., acetonitrile and tert-butylbenzene) employed in this study were all of analytical grade and purchased from Sigma-Aldrich (St. Louis, MO, USA).

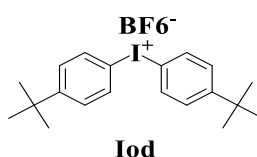

Iod
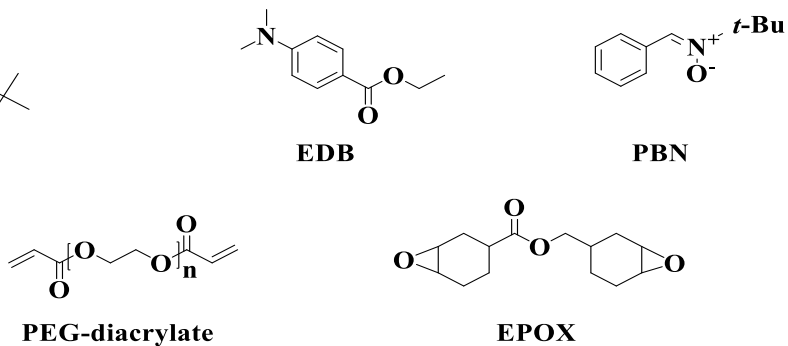

EPOX

Scheme 2. The chemical structure of other compounds used in this study.

\subsection{Free Radical Photopolymerization (FRP) and Cationic Photopolymerizations} (CP) Process Monitored by Real Time Fourier Transformed Infrared Spectroscopy (RT-FTIR) under LED 375nm or 405nm

In this study, different three-component photoinitiation systems (PIS) were prepared with bis-chalcones/Iod/amine combinations for FRP and CP under near UV or visible light of LED 375nm and 405nm. The weight contents of the different components were 
calculated from the monomers (PEG-diacrylate or EPOX) content and kept at $1.5 \% / 1.5 \% / 1.5 \%(\mathrm{w} / \mathrm{w} / \mathrm{w})$, respectively. Moreover, the photosensitive formulations of all samples were dropped between two polypropylene films (thickness $\sim 20 \mu \mathrm{m}$ ) with one drop of resin in laminate for the FRP, sandwiching the formulation in the middle to reduce the $\mathrm{O}_{2}$ inhibition. For the CP of EPOX films (thickness $\sim 20 \mu \mathrm{m}$ ) the experiments were carried out under air using a polished film as substrate with one drops of resin. The evolution the epoxy or acrylate functions were continuously monitored by real time Fourier transform infrared spectroscopy (RT-FTIR, JASCO FTIR 4100) at the characteristic peaks around $790 \mathrm{~cm}^{-1}$ and $1630 \mathrm{~cm}^{-1}$, respectively [39].

\subsection{UV-Visible Absorption Properties, Photolysis Properties and Fluorescence}

\section{Properties of Bis-chalcones}

Using a JASCO V730 spectrophotometer, the UV-visible absorption properties of the 10 different bis-chalcones and photolysis of the bis-chalcones /Iod/amine based threecompound PISs could be studied. Absorption properties of samples were analyzed in acetonitrile with the concentration of $1 \times 10^{-5} \mathrm{M}$. Furthermore, LED@375 nm was used as the light source for photolysis experiments. In addition, $5 \times 10^{-5} \mathrm{M}$ of bis-chalcones and $0.01 \mathrm{M}$ of iodonium salt (Iod) and EDB were used during the photolysis process. Apart from that, their fluorescence properties were studied in acetonitrile with a concentration of $1 \times 10^{-5} \mathrm{M}$ using JASCO FP-6200 spectrofluorimeter [40].

\subsection{Cyclic Voltammetry Experiments to Measure the Redox Potentials of Bis- chalcones.}

The redox potentials (oxidation potential $\mathrm{E}_{\mathrm{ox}}$ and reduction potential $\mathrm{E}_{\mathrm{red}} \mathrm{vs.} \mathrm{SCE}$ ) of bis-chalcones were measured in acetonitrile by cyclic voltammetry while using tetrabutylammonium hexafluorophosphate $(0.1 \mathrm{M})$ as the supporting electrolyte. A platinum electrode was used as a working electrode and a saturated calomel electrode (SCE) was used as a reference electrode. Free energy change ( $\Delta \mathrm{G}^{\mathrm{S1}}$ Iod or $\left.\Delta \mathrm{G}^{\mathrm{S1}}{ }_{\mathrm{EDB}}\right)$ for the electron transfer reaction was calculated from equation 1 or 2 (eq. 1 or eq. 2), where $\mathrm{E}_{\mathrm{ox}}, \mathrm{E}_{\mathrm{red}}$ and $\mathrm{E}_{\mathrm{S} 1}^{*}$ are the oxidation potential of the electron donor, the reduction 
potential of the electron acceptor and the excited state energy level (calculated from the crossing point of UV-visible and fluorescence spectra), respectively. The reduction potential of iodonium was $-0.7 \mathrm{eV}$ and the oxidation potential of EDB was $1.0 \mathrm{eV}$ according to literature data [41].

$$
\begin{aligned}
\Delta G^{S 1} \text { Iod } & =E_{o x}-(-0.7)-E^{*} \mathbf{s} \\
\Delta G^{S 1} \text { EDB } & =1.0-E_{r e d}-E^{*}{ }^{*} 1
\end{aligned}
$$

\subsection{Electron Spin Resonance (ESR) Spin Trapping (ESR-ST) Experiments}

A X-band spectrometer (Bruker EMX-plus) was used to carry out the ESR-ST experiments. The generated radicals were observed at room temperature in $\mathrm{N}_{2}$ saturated tert-butylbenzene solutions upon LED@375nm irradiation light while trapping by $N$ tert-butyl-phenylnitrone(PBN). ESR spectra simulations were performed by WINSIM software [42].

\subsection{D Printing Experiments}

Photosensitive formulations containing PEG-diacrylate and the three-compound PIS in solvent-free conditions were polymerized under air with a homemade glass tank using computer programmed laser diode @ 405nm (Thorlabs) with a spot size of about $50 \mu \mathrm{m}$. The obtained 3D patterns were analyzed through a numerical optical microscope (DSXHRSU from Olympus Corporation, Tokyo, Japan).

\subsection{Swelling Kinetics of PEG-polymers Prepared with Bis-chalcones 5 and 9 based}

\section{Three-compound PISs}

The swelling kinetics of PEG-polymers prepared by the novel PISs were investigated by soaking the samples in deionized water at room temperature for $24 \mathrm{~h}$. Then, the products $(n=3)$ were taken out from deionized water and the residual water on the surface of the products was blotted by filter paper. Thereafter, the wet weight of each polymerization product was measured $\left(\mathrm{W}_{\mathrm{t}}\right)$ and compared to the initial wet weight $\left(\mathrm{W}_{0}\right)$. The swelling ratio $(\mathrm{Sr})$ was defined according to equation 3 [43]. After that, put the 
swollen products in an oven at $50{ }^{\circ} \mathrm{C}$ for $1 \mathrm{~h}$ to remove the absorbed water, and then compare the volume changes of the patterns in the cycle: before water swelling $\left(\mathrm{V}_{1}\right)$, after water swelling $\left(\mathrm{V}_{2}\right)$, after heating $\left(\mathrm{V}_{3}\right)$ and calculated the increase rate of volume after swelling $(R)$ according to equation 4 [44].

$$
\begin{aligned}
& \operatorname{Sr}(\%)=(\mathrm{Wt}-\mathrm{Wo}) / \mathrm{Wo} \times 100 \\
& R(\%)=\left(\mathrm{V}_{2} / \mathrm{V}_{1}\right) \times 100
\end{aligned}
$$

\subsection{Shape-Memory via Swelling and Dehydration Induced Actuation (4D behavior)}

The reversible temporarily deformation effect of the polymerization products induced by bis-chalcone/Iod/amine $(1.5 \% / 1.5 \% / 1.5 \%, \mathrm{w} / \mathrm{w} / \mathrm{w})$ based three-component PISs upon LED 375nm were measured via swelling and dehydration induced actuation: at first, the product was immersed into water for $1 \mathrm{~min}$ at room temperature; after that, it was took out from water and then put into oven around $100{ }^{\circ} \mathrm{C}$ for $10 \mathrm{~min}$ to remove the contained water; finally, the product was removed into room temperature to recovery their initial shapes [45].

\section{Results and Discussion}

3.1. Synthesis of bis-chalcones 1-10.

In this series of ten bis-chalcones, only two of the selected chalcones, namely bischalcone 8 and bis-chalcone 10, have previously been reported in the literature [46-47]. Besides the synthetic route used to access to these structures is different from that used in this work (see schemes 3 and 4). 


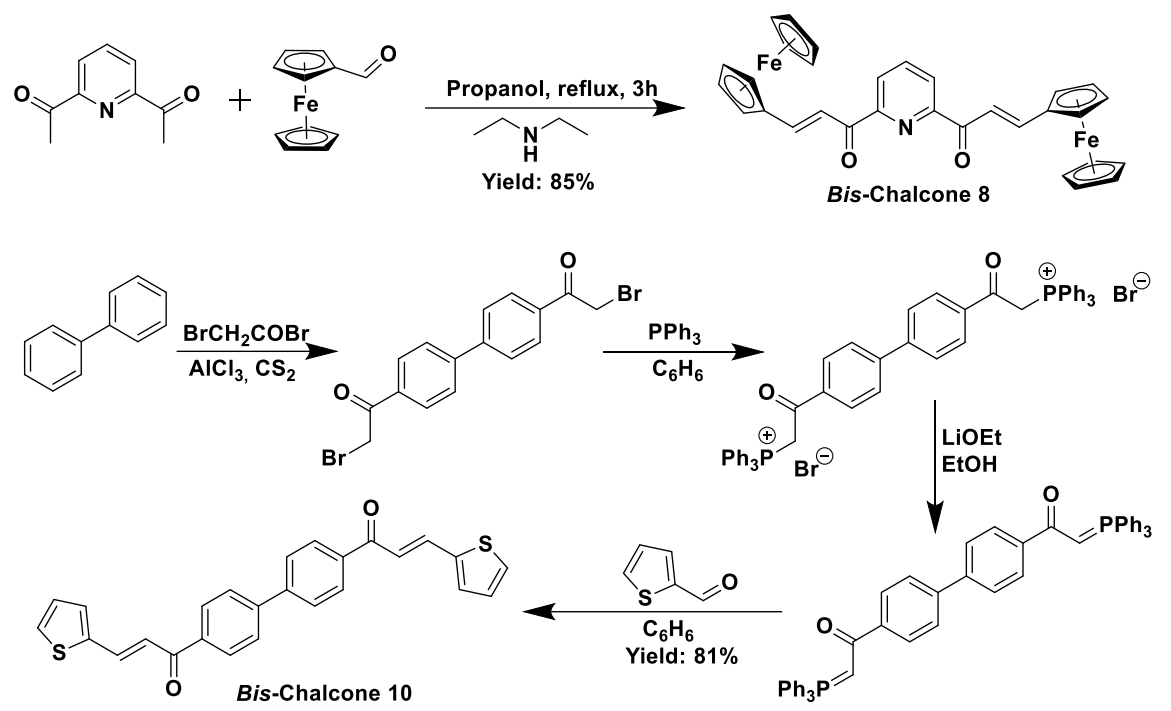

Scheme 3. Previously reported synthetic routes to bis-chalcones 8 and 10 .

In our case, the Claisen-Schmidt condensation proved to be a straightforward route to obtain all bis-chalcones 1-10 and strong basic conditions (aq. $40 \% \mathrm{KOH}$ ) were used. All compounds could be obtained with reactions yields ranging from 58 to $91 \%$ (See scheme 4). Especially, contrarily to the previous synthesis reported for bis-chalcone 10 where a four-step procedure was used, in our newly developed procedure, bis-chalcone 10 could be prepared in one step starting from commercially available reagents. Detailed synthesis procedures and characterizations of all bis-chalcones are presented in the SI. 
Piperidinone Based Bis-Chalcones
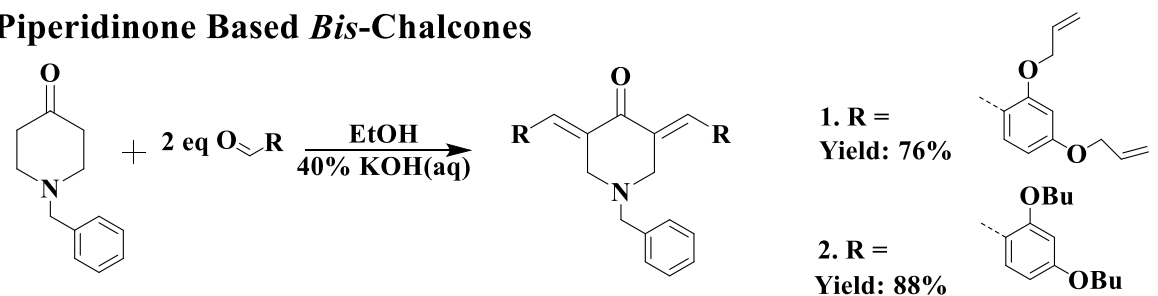

Tetrahydrothiopyranone Based Bis-Chalcones<smiles>O=C1CCSCC1</smiles><smiles>[R]C=C1CSCC(=C[R])C1=O</smiles>

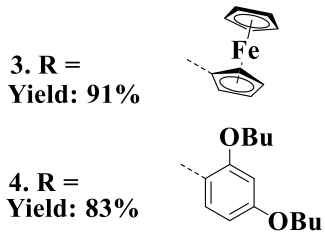

Pyridines Based Bis-Chalcones

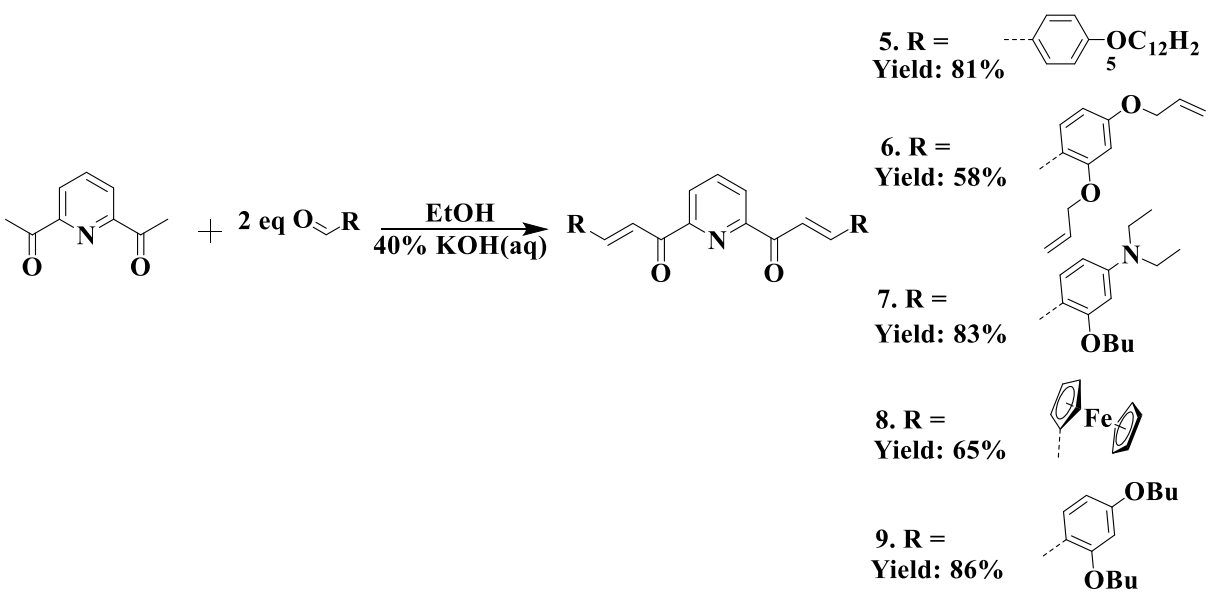

Biphenyl Based Bis-Chalcone

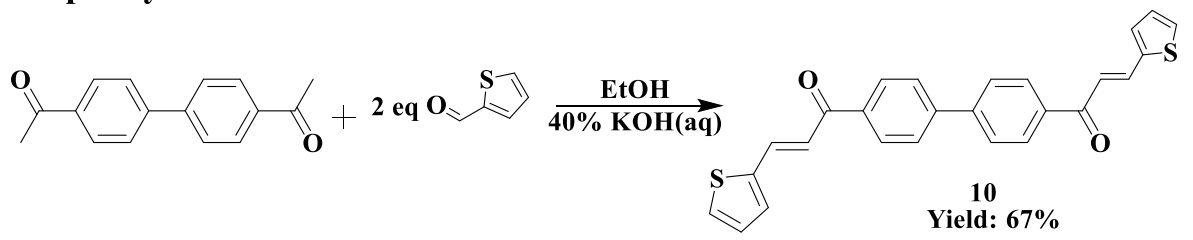

Scheme 4. Synthetic routes to bis-chalcones 1-10

3.2. UV-visible Absorption Properties of the Bis-chalcones in Acetonitrile

The ground state absorption spectra of 10 novel proposed photoinitiators in acetonitrile were recorded and the spectra are shown in Figure 1, while their absorption maxima $\left(\lambda_{\max }\right)$ and extinction coefficients $\left(\varepsilon_{\max }\right)$ at $\lambda_{\max }$ and at the emission wavelength of the LED@375 nm and LED@405 nm are summarized in the Table 1. Except the bischalcone 7 whose maximum absorption peak appeared around $430 \mathrm{~nm}$, the maximum absorption wavelength of the other PIs was below $380 \mathrm{~nm}$, guaranteeing a good overlap with the emission spectra of the LED@375 nm and LED@405 nm used in this work. 
Remarkably, these PIs exhibited high extinction coefficients $\left(\varepsilon_{\max }\right)$ in the near UV and visible light (e.g., $13700 \mathrm{M}^{-1} \mathrm{~cm}^{-1}$ and $24000 \mathrm{M}^{-1} \mathrm{~cm}^{-1}$ for bis-chalcone 9 at $375 \mathrm{~nm}$ and $405 \mathrm{~nm}$ ) corresponding to $\pi-\pi^{*}$ electronic transitions (these $\pi$ and $\pi^{*}$ frontier orbitals are also well observed in the molecular modeling results; Figure S1 in supporting information).

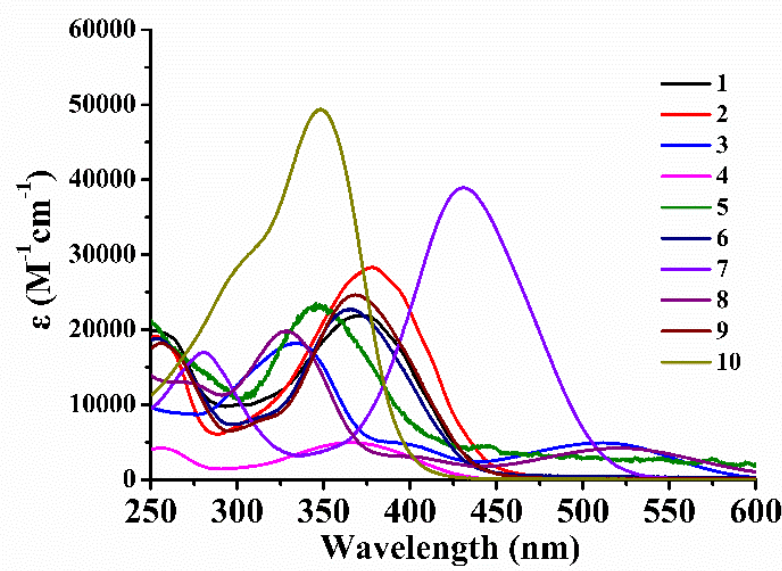

Figure 1. The UV-visible absorption spectra of bis-chalcones 1-10 in acetonitrile.

\begin{tabular}{|c|c|c|c|c|}
\hline Bis-chalcones & $\lambda_{\max }(\mathrm{nm})$ & $\varepsilon_{\max }\left(M^{-1} \mathrm{~cm}^{-1}\right)$ & $\varepsilon_{@ 405 \mathrm{~nm}}\left(\mathrm{M}^{-1} \mathrm{~cm}^{-1}\right)$ & $\varepsilon_{@ 375 \mathrm{~nm}}\left(\mathrm{M}^{-1} \mathrm{~cm}^{-1}\right)$ \\
\hline 1 & 370 & 21900 & 12740 & 21800 \\
\hline 2 & 380 & 28200 & 19730 & 28000 \\
\hline 3 & 332 & 18200 & 4420 & 5800 \\
\hline 4 & 369 & 4980 & 2550 & 4800 \\
\hline 5 & 347 & 23150 & 6800 & 16500 \\
\hline 6 & 364 & 22700 & 10070 & 21500 \\
\hline 7 & 430 & 38940 & 26420 & 8500 \\
\hline 8 & 330 & 19840 & 2960 & 4000 \\
\hline 9 & 370 & 24650 & 13670 & 24000 \\
\hline 10 & 350 & 49350 & 2220 & 24500 \\
\hline
\end{tabular}


Table 1. Light absorption properties of bis-chalcones in acetonitrile: maximum absorption wavelengths $\lambda_{\max }$; extinction coefficients at $\lambda_{\max }\left(\varepsilon_{\max }\right)$ and extinction coefficients at the emission wavelength of the LED@405 nm $(\varepsilon @ 405 \mathrm{~nm})$ and LED@375 $\mathrm{nm}(\varepsilon @ 375 \mathrm{~nm})$.

3.3. Photopolymerization Kinetics of the Proposed Bis-chalcones based ThreeComponent PISs.

\subsubsection{Free radical polymerization (FRP) kinetics of PEG-acrylate.}

For the polymerization of PEG-acrylate monomer, photoinitiation abilities of bischalcone/Iod/amine $(1.5 \% / 1.5 \% / 1.5 \%, \mathrm{w} / \mathrm{w} / \mathrm{w})$ based three-compound PISs were studied using RT-FTIR in thin films upon irradiation with LED@375nm and LED@405nm at room temperature. Typical final acrylate function conversions (FC) vs irradiation time profiles are given in Figure 2 and the FCs are outlined in Table 2. As shown in Figure 2a, under the LED@375nm, the polymerization profiles of all the other PISs are much better than the blank control which is only initiated by the co-initiator (Iod, $1.5 \%, \mathrm{w} / \mathrm{w})$ and the electron donor (amine, 1.5\%, w/w) (FC 49\%). It demonstrates the huge effect of the presence of the bis-chalcones. Furthermore, in comparison with the effectiveness in terms of the final monomer conversions (Table 2) and the rates of polymerization (the initial slope of the curves), bis-chalcones 2, 5, 6, and 9 proved to be excellent candidates to boost the kinetics of the polymerization for samples in thin films in laminate under LED@375nm (e.g., the FCs of them were 89\%, 86\%, 95\% and $89 \%$, respectively), matching with their higher extinction coefficient at $375 \mathrm{~nm}$.

When irradiating with the LED@405nm and comparing with the blank control experiment, better photopolymerization kinetics were observed for the bis-chalcones, except bis-chalcones 3 and 4. Remarkably, the PIS of bis-chalcones 7 and 9 achieved the best effectiveness (see figure $2 b$ ) which can be assigned to their high molar extinction coefficients at $405 \mathrm{~nm}$ (e.g. $26420 \mathrm{M}^{-1} \mathrm{~cm}^{-1}$ for chalcone $7,13670 \mathrm{M}^{-1} \mathrm{~cm}^{-1}$ for bis-chalcone 9, respectively, see table 1). More interestingly, the systems of bischalcones 3 and 8 (ferrocene-based bis-chalcones) cannot be polymerized under the irradiation of either LED@375nm or LED@405nm, which was due to the ferrocene derivatives are mainly used to induce the polymerization of epoxy compounds according to the literature [48]. 
In summary, a good solubility of all these systems was found in PEG-acrylate in solvent-free conditions and all the formulations were colored, the color ranging from yellow to pale yellow. Furthermore, bis-chalcones 2, 5, 6, 7 and 9 were selected from the 10 different PIs as representative structures for the more detailed investigations.

(a)

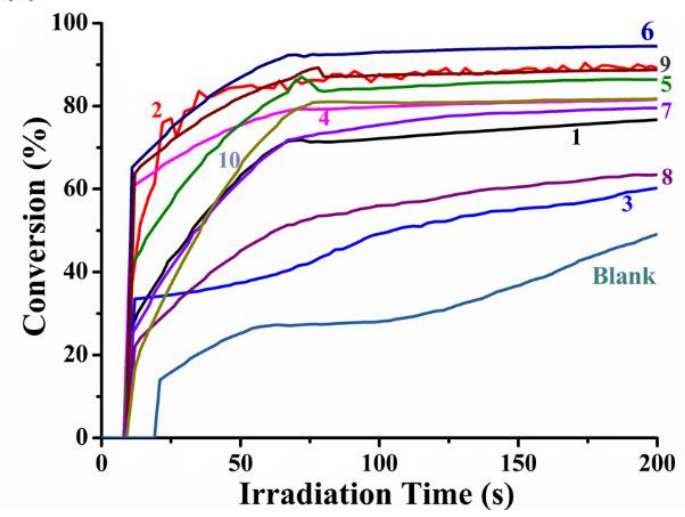

(b)

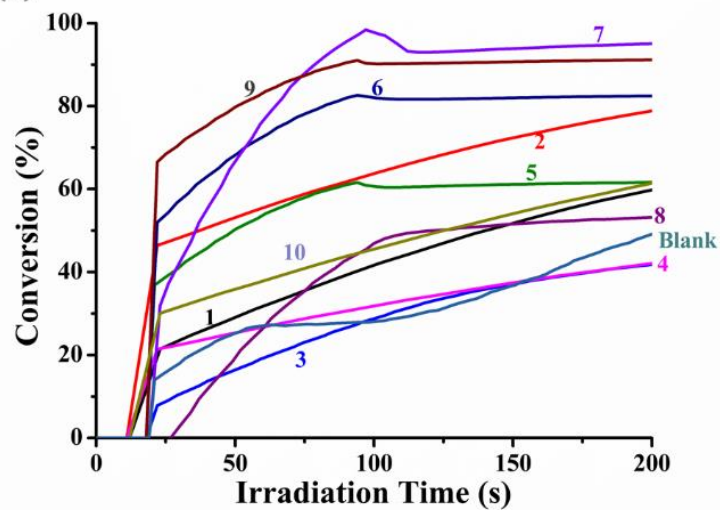

Figure 2. Photopolymerization profiles of $\mathrm{PEG}$-acrylate (conversion of $\mathrm{C}=\mathrm{C}$ bonds vs irradiation time) initiated by bis-chalcones (1-10), iodonium salt (Speedcure 938) and amine (Speedcure EDB) in laminate in thin films, at the same weight ratio bis-chalcones (1-10): Speedcure 938: $\mathrm{EDB}=1.5 \%: 1.5 \%: 1.5 \%, \mathrm{w} / \mathrm{w} / \mathrm{w}$, (a) exposure to a LED@375nm; (b) exposure to a LED@405nm, the irradiation starts for t=10s.

\begin{tabular}{|c|c|c|c|c|c|c|c|}
\hline \multicolumn{8}{|c|}{ Bis-chalcones initiating systems in PEG-acrylate } \\
\hline \multirow{5}{*}{ LED@375nm } & Bis-chalcones & 1 & 2 & 3 & 4 & 5 & 6 \\
\cline { 2 - 8 } & FCs & 77 & 89 & 60 & 82 & 86 & 95 \\
\cline { 2 - 9 } & Bis-chalcones & 7 & 8 & 9 & 10 & Blank & \\
\cline { 2 - 9 } & FCs & 80 & 64 & 89 & 82 & 49 & \\
\hline \multirow{5}{*}{ LED@405nm } & Bis-chalcones & 1 & 2 & 3 & 4 & 5 & 6 \\
\cline { 2 - 9 } & FCs & 60 & 79 & 42 & 42 & 62 & 83 \\
\cline { 2 - 9 } & Bis-chalcones & 7 & 8 & 9 & 10 & Blank & \\
\cline { 2 - 8 } & FCs & 95 & 53 & 91 & 62 & 49 & \\
\hline
\end{tabular}

Table 2. Summary of the FCs for the PEG-diacrylate monomer while using the threecomponent PISs based on bis-chalcone $(1.5 \%$, w/w)/iodonium salt (Speedcure 938, 1.5\%, w/w)/amine (Speedcure EDB, 1.5\%, w/w) in thin films upon LED@375nm and LED@405nm. The blank corresponds iodonium/amine initiating systems without chalcones. 


\subsubsection{Cationic polymerization (CP) kinetics of EPOX.}

Due to the ferrocene-based bis-chalcones 3 and 8 are mainly used to induce the polymerization of epoxy compounds, the proposed bis-chalcones in combination with Iod and EDB have also been tested for the CP of EPOX in thin films $(20 \mu \mathrm{m})$ which was performed under air. The three compound PISs based on bis-chalcones /Iod/amine combinations $(1.5 \% / 1.5 \% \mathrm{w} / 1.5 \%, \mathrm{w} / \mathrm{w} / \mathrm{w})$ achieved good polymerization efficiencies in terms of final epoxy function conversions (FCs) when irradiated with the LED @ $375 \mathrm{~nm}$ as a mild irradiation source (Figure 3, Table 3). In the same irradiation conditions, Iod and EDB alone were also tested and proved to be poor very photoinitiators when used as single component, highlighting the crucial role of the three-component systems for the overall performance. The trend of efficiency for the $\mathrm{CP}$ is not directly linked to their respective absorption properties ( $\varepsilon @ 375 \mathrm{~nm})$ that follow another trend (i.e. $4>2>1,5,9,10>6>3>10>7>8$ ). For example, bischalcones 4 is the most efficient PI for the CP but it is not characterized by the highest molar absorption coefficient ( $\varepsilon @ 375 \mathrm{~nm} \sim 4800 \mathrm{M}^{-1} . \mathrm{cm}^{-1}$; Table 1). Therefore, the ability of these PISs is also related to their photochemical reactivity with the iodonium salt and the amine as well as the ability of the generated radical cation (bis-chalcone ${ }^{\bullet+}$ ) to initiate the $\mathrm{CP}$ process (see the chemical mechanisms below).

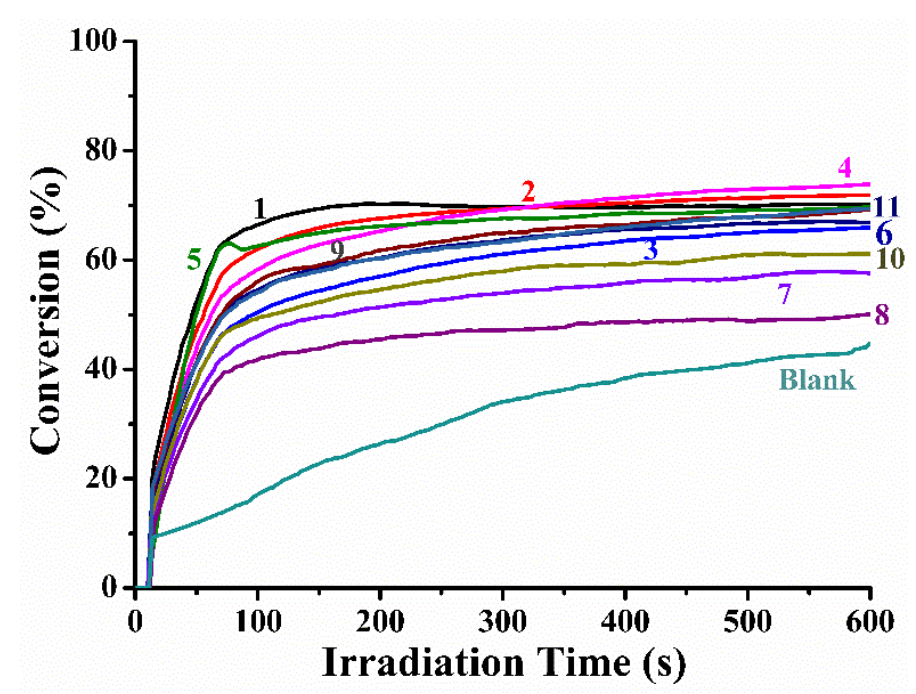

Figure 3. Photopolymerization profiles of EPOX (conversion of epoxy functions vs irradiation time) initiated by bis-chalcone (1-10), iodonium salt (Speedcure 938) and amine (Speedcure EDB) under air in thin films exposure to a LED@375nm, at the same 
weight ratio bis-chalcones (1-10): Speedcure 938: $\mathrm{EDB}=1.5 \%: 1.5 \%: 1.5 \%$, w/w/w, the irradiation starts for $\mathrm{t}=10 \mathrm{~s}$.

\begin{tabular}{|c|c|c|c|c|c|c|}
\hline \multicolumn{7}{|c|}{ Bis-chalcone initiating systems in EPOX } \\
\hline Bis-chalcones & 1 & 2 & 3 & 4 & 5 & 6 \\
\hline FCs & 70 & 72 & 66 & 74 & 70 & 67 \\
\hline Bis-chalcones & 7 & 8 & 9 & 10 & Blank & \\
\hline FCs & 58 & 50 & 70 & 70 & 45 & \\
\hline
\end{tabular}

Table 3. Summary of the FCs for the epoxy functions in EPOX monomer while using the three-component PISs based on bis-chalcone $(1.5 \%, \mathrm{w} / \mathrm{w}) /$ iodonium salt (Speedcure 938, 1.5\%, w/w)/amine (Speedcure EDB, 1.5\%, w/w) in thin films upon LED@ 375nm. The blank corresponds iodonium/amine initiating systems without chalcones.

\subsubsection{D printing experiments based on the proposed three-component PISs.}

Laser write experiments were successfully performed with the proposed bischalcones 5 and 9 based three-component PISs in combination with the PEG-diacrylate monomer using laser diode about 50 um and light source of LED@405 nm, which is very reactive for the free radical polymerization of (meth)acrylates. The other three systems based on bis-chalcones 2, 6 and 7 can also initiate the photopolymerization under the same conditions, but 3D products with an acceptable spatial resolution could not be obtained. As shown in Figure 4, it is noticeable that the high photosensitivity of PISs based on bis-chalcones 5 and 9/Iod/amine enables PEG-diacrylate monomers to be effectively polymerized in 3D objects, resulting in a stable 3D letter pattern ("LHI") with spatial resolution. Furthermore, it took shorter irradiation time for the system based on bis-chalcone 5 in 3D printing than that of bis-chalcone 9, and all of them can be completed within 3 minutes. 
(a)

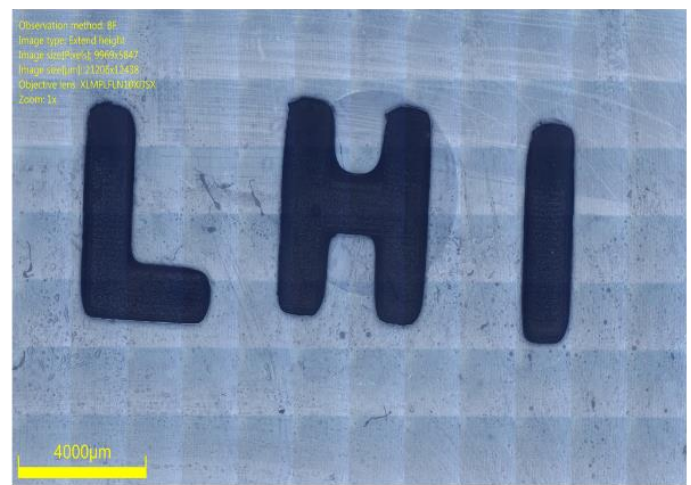

(c)

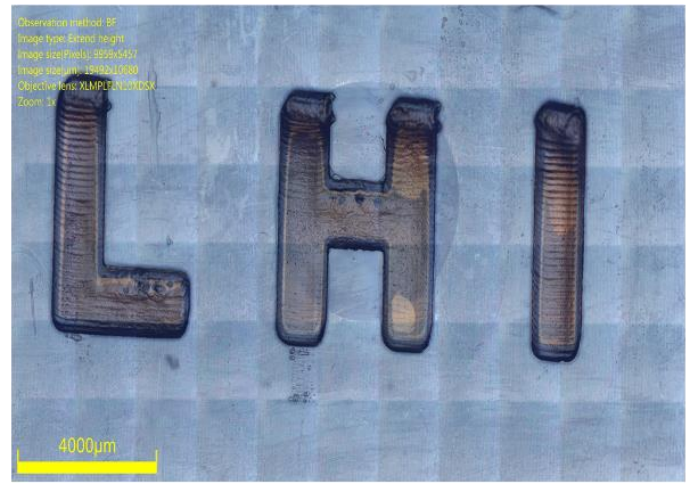

(b)

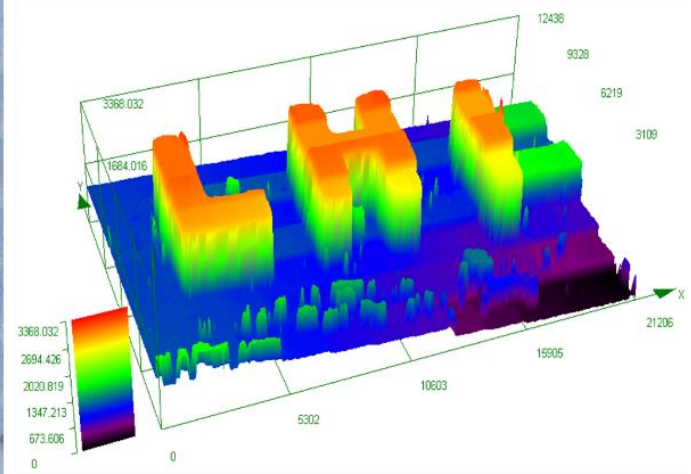

(d)

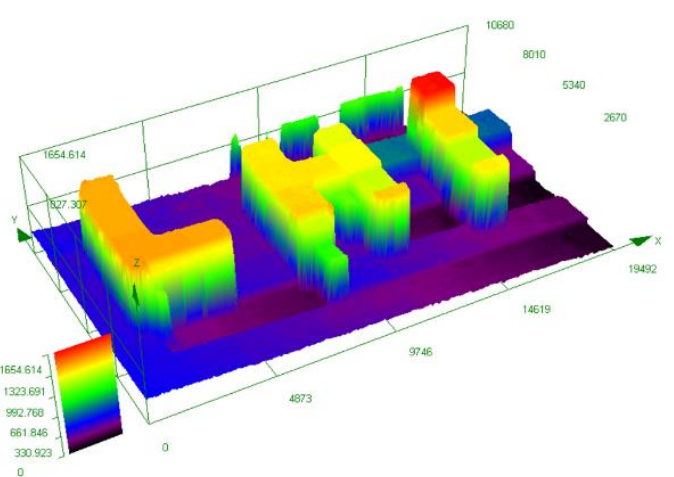

Figure 4. Free radical photopolymerization experiments for laser write initiated bischalcones based three-component photoinitiating systems using PEG-diacrylate as the monomer. Characterization of the 3D patterns by numerical optical microscopy: (left) top surface morphology and (right) 3-D overall appearance of 3D patterns of bischalcones/Iod/EDB $(1.5 \% / 1.5 \% / 1.5 \%, \mathrm{w} / \mathrm{w} / \mathrm{w})$ in PEG-diacrylate: (a) (b) for bischalcone 5/Iod/EDB; (c) (d) for bis-chalcone 9/Iod/EDB.

\subsection{Proposed Chemical Mechanisms}




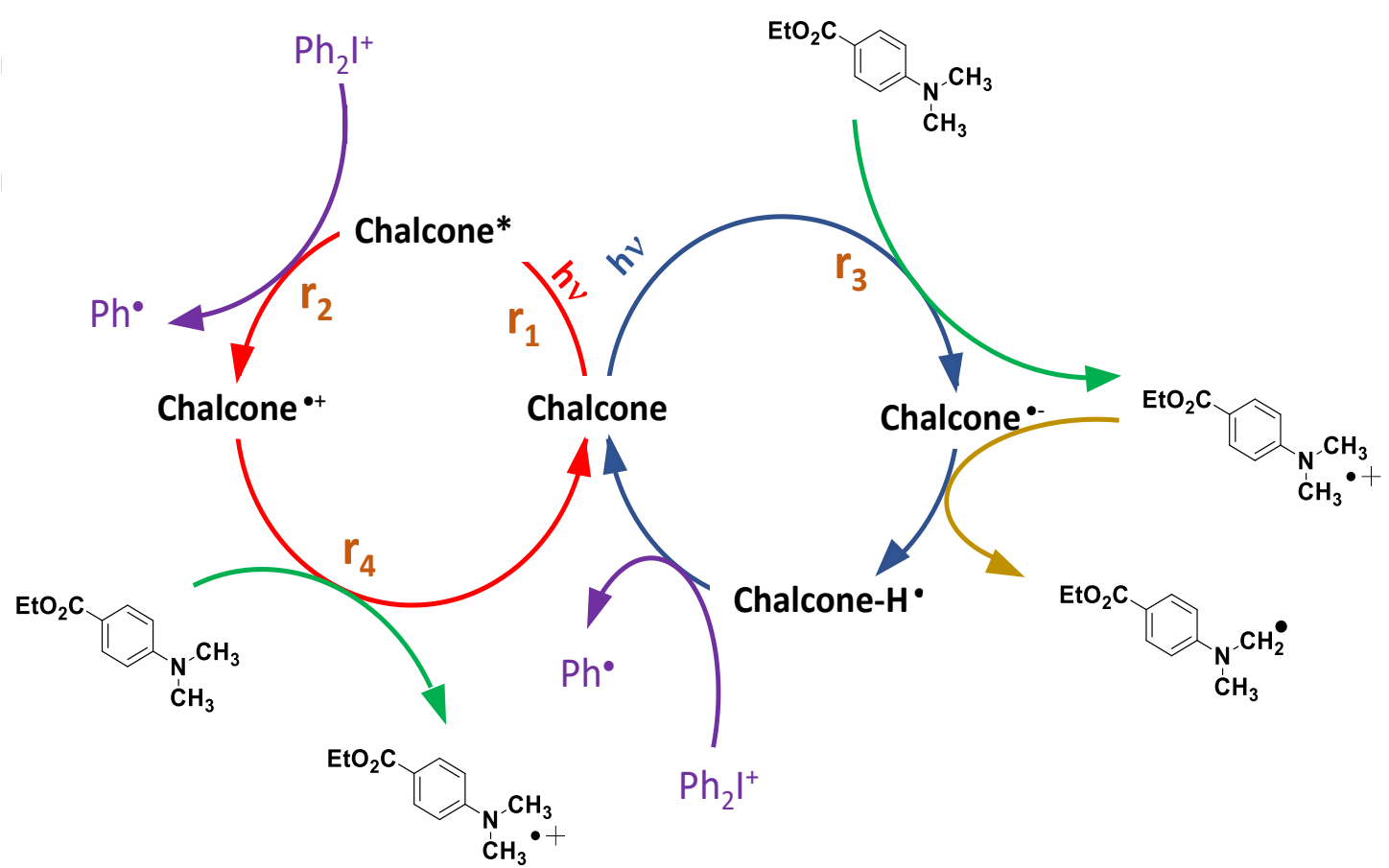

Scheme 5. Proposed photoinitiation mechanisms of bis-chalcones/Iod/amine initiating systems.

3.4.1 Steady state photolysis of bis-chalcones characterized by UV-visible absorption spectroscopy and the consumption of bis-chalcones during photolysis

The steady-state photolysis experiments of the bis-chalcones 5 and 9 in the presence of an iodonium salt and/or an amine in acetonitrile have been carried out to better understand the interaction of iodonium salt or amine with bis-chalcone in the three-component system [49]. Upon irradiation with a LED@375 nm, obvious and significant declines of the UV-visible absorption intensity for bis-chalcone 5 were observed both in the three-compound systems (bis-chalcone 5/Iod/amine) and the twocompound systems (bis-chalcone 5/Iod and bis-chalcone 5/amine) (see in Figure 5(a) (c)), and all of them completely decomposed within 20s. Based on the abovementioned steady state photolysis process, we summarized the consumption of bis-chalcone 5 vs. the irradiation time in Figure 5(d). For the same irradiation time, it is clear that the highest consumption of bis-chalcone 5 achieved by the bis-chalcone/amine combination, closing to that reached when using the three-component PIS (bischalcone/Iod/amine), while the two-component PIS based on bis-chalcone 5/Iod 
combinations achieved the lowest consumption (e.g. the consumption of bis-chalcone $5=35 \%$ for bis-chalcone 5/amine and $32 \%$ for bis-chalcone 5/Iod/amine vs. $16 \%$ for bis-chalcone 5/Iod).

According to the proposed mechanism shown in Scheme 5, the reaction process can be divided into two parts: (1) the bis-chalcones combined with the iodonium salt and (2) the bis-chalcone combined with the aromatic amine [25]. The abovementioned results of bis-chalcone 5 proposed that the interaction of bis-chalcone 5/amine combination was more efficient than that of bis-chalcone 5/Iod combination.

(a)

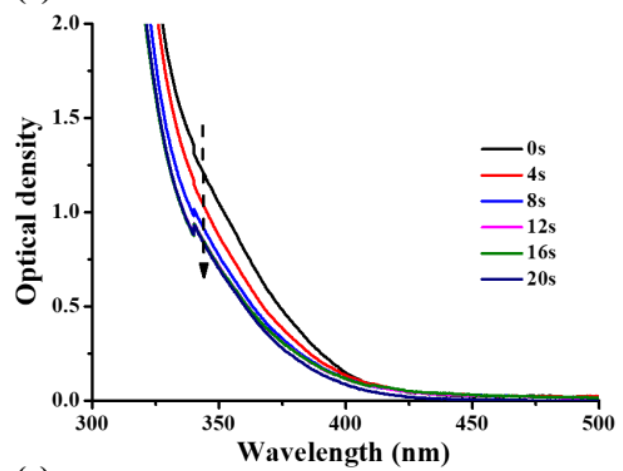

(c)

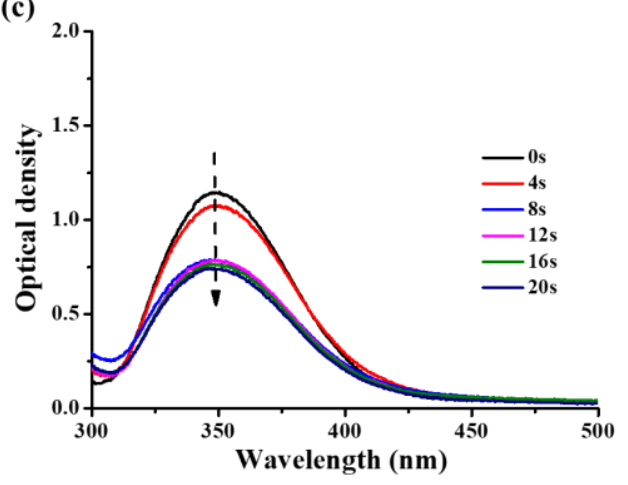

(b)

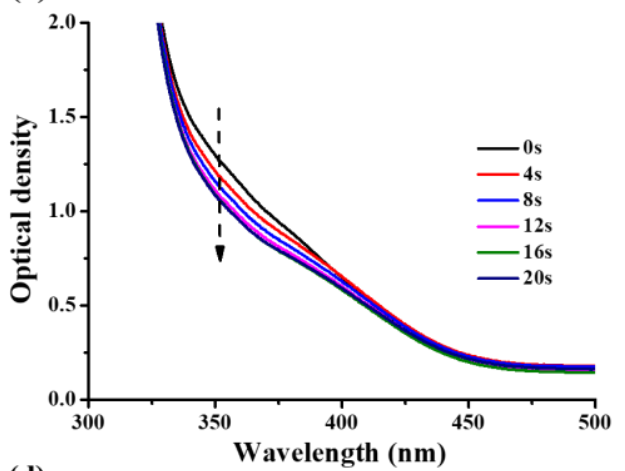

(d)

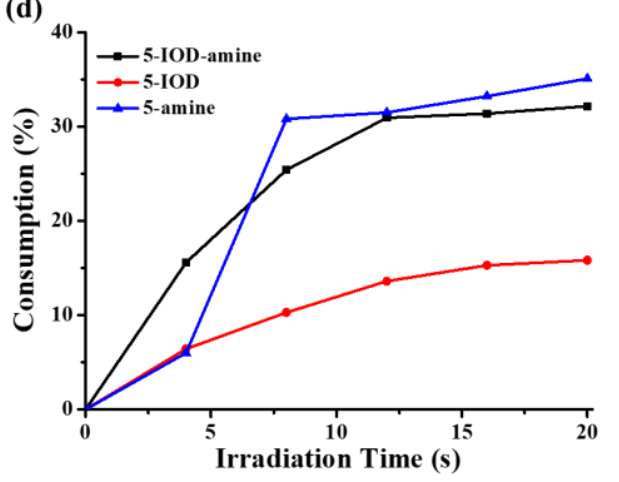

Figure 5. Photolysis of bis-chalcone $5\left(5 \times 10^{-5} \mathrm{M}\right.$ in acetonitrile) with (a) iodonium salt (Speedcure 938, 0.01M) and amine (Speedcure EDB, 0.01 M); (b) iodonium salt (Speedcure 938, 0.01M); (c) amine (Speedcure EDB, $0.01 \mathrm{M}$ ) upon exposure to LED@375nm under air in acetonitrile; (d) consumption of bis-chalcone 5 during the photolysis process.

For the three-component systems based on bis-chalcone 9, we proposed that Scheme 5 would also occur, generating different radicals during photolysis. Similarly, in the presence of Iod and/or amine, significant changes could be detected in the 
absorption spectra of bis-chalcone 9 and its photolysis (irradiation time $\leqq 10$ s) was faster than that of bis-chalcone 5 (irradiation time $\leqq 20 \mathrm{~s}$ ) due to its higher molar extinction coefficients at $375 \mathrm{~nm}$ (see Table 1). It is remarkable from Figure 6(d) that the consumption of bis-chalcone 9 achieved by the three-component PIS (bis-chalcone 9/Iod/amine) was slightly higher than that observed for the two-component PIS based on bis-chalcone 9/Iod and bis-chalcone 9/amine combinations (e.g. the consumption of bis-chalcone $9=17 \%$ for bis-chalcone 9/Iod/amine vs. $14 \%$ for bis-chalcone $9 / \operatorname{Iod}$ or $12 \%$ fo bis-chalcone 9/amine) which means that the interaction of the three-component PIS based on bis-chalcone 9 was more efficient than that of the two-component PIS.
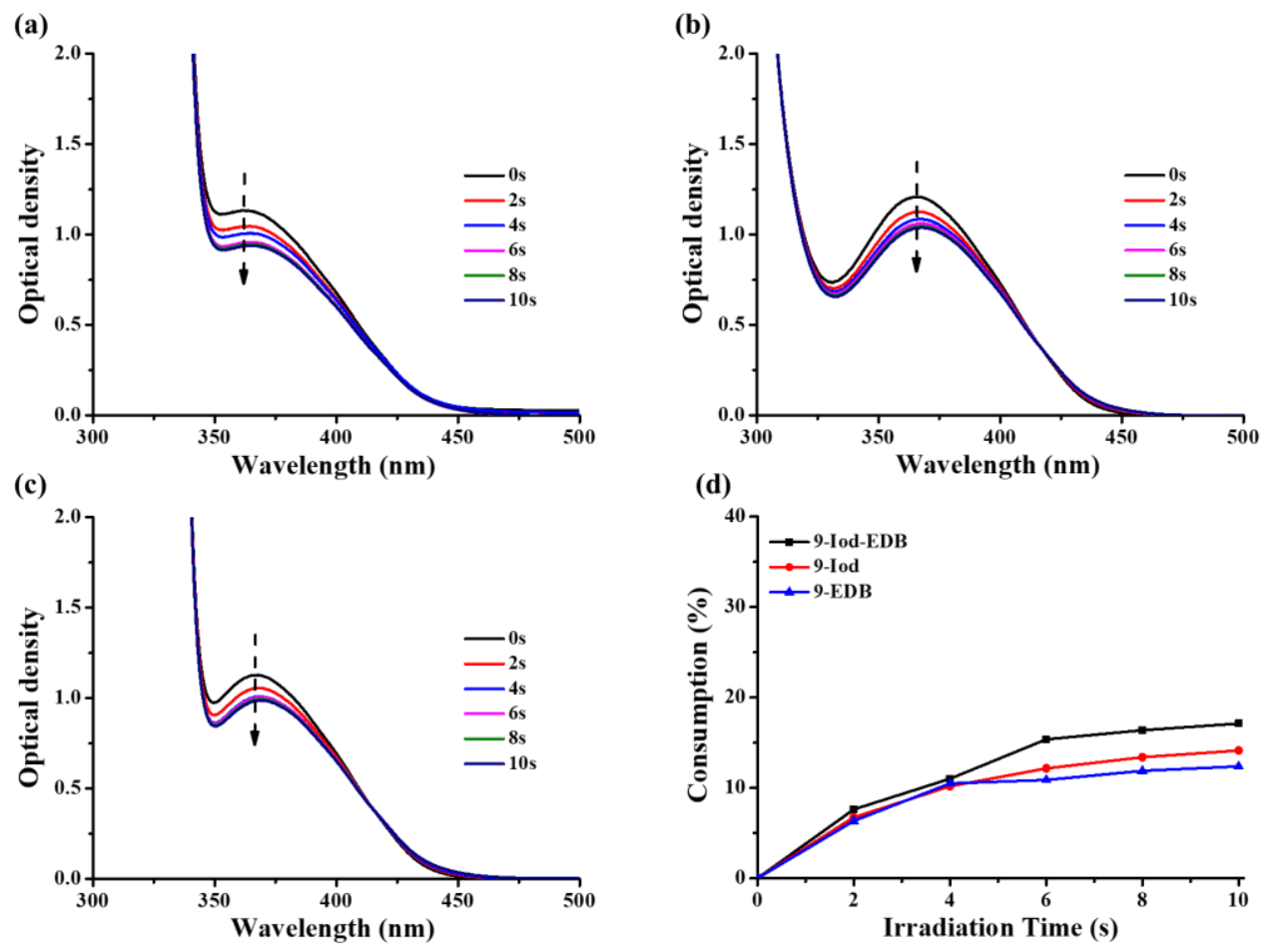

Figure 6. Photolysis of bis-chalcone $9\left(5 \times 10^{-5} \mathrm{M}\right.$ in acetonitrile) with (a) iodonium salt (Speedcure 938, 0.01M) and amine (Speedcure EDB, 0.01 M); (b) iodonium salt (Speedcure 938, 0.01M); (c) amine (Speedcure EDB, $0.01 \mathrm{M}$ ) upon exposure to LED@375nm under air in acetonitrile; (d) consumption of bis-chalcone 9 during the photolysis process

3.4.2. Fluorescence quenching for Bis-chalcones with the addition of iodonium salt or amine. 
The fluorescence spectra of bis-chalcones 5 and 9 in acetonitrile were also recorded and the data are presented in Figure 7. Obviously, the first singlet excited state energy $\left(E_{\mathrm{S} 1}\right)$ can be determined from the crossing point between the absorption and the fluorescence spectra (e.g. $\mathrm{E}_{\mathrm{S} 1}=3.03 \mathrm{eV}$ for bis-chalcone 5, $2.83 \mathrm{eV}$ for bis-chalcone 9; Table 4).

(a)

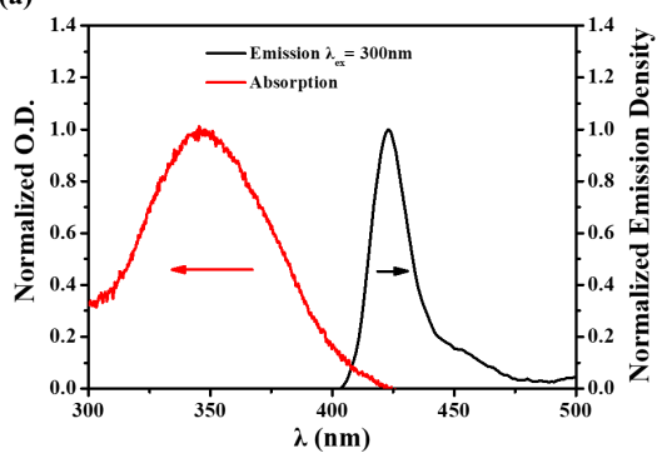

(b)

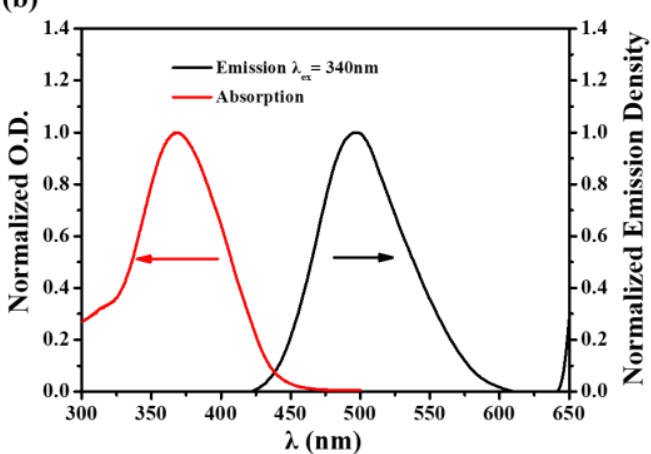

Figure 7. Singlet state energy determination in acetonitrile of (a) bis-chalcone 5; (b) bis-chalcone 9.

Fluorescence quenching experiments for bis-chalcones 5 and 9 were conducted in acetonitrile to seek the theoretical feasibility of the interactions of bis-chalcone/Iod and bis-chalcone/amine [40]. The intensity of the emission peak of bis-chalcone 5 decreased with the addition of iodonium salt or amine, a linear curve can be fitted from the fluorescence quenching processes (Table 4). For bis-chalcone 9, the iodonium salt and the amine can also act as good quenchers, and significant changes could be observed (see Figure 8). These results demonstrated that the addition of iodonium salt or amine can lead to interaction with the chromophore in the excited singlet state. Furthermore, favorable fluorescence quenching processes of the excited singlet states by iodonium salt or amine are also shown by the value of the Stern-Volmer coefficients $\left(\mathrm{K}_{\mathrm{SV}}\right.$, the slope of the curve, Table 4) as well as the electron transfer quantum yield ( $\phi_{\mathrm{et}}$, Table 4$)$ for the expected electron transfer reaction between the bis-chalcone and Iod or amine that can be calculated applying the equation 5. Compared to bis-chalcone 5, bischalcone 9 showed higher electron transfer quantum yields $\left(\phi_{\mathrm{et}}\right)[13]$.

$$
\Phi^{\mathrm{et}} \operatorname{Iod}=\mathrm{K}^{\mathrm{sv}} \operatorname{Iod} *[\operatorname{Iod}] /\left(1+\mathrm{K}^{\mathrm{sv}} \operatorname{Iod} *[\operatorname{Iod}]\right)
$$


(a)

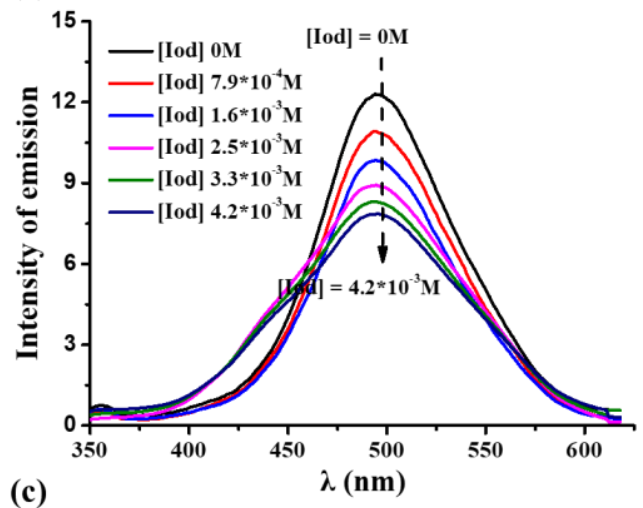

(c)

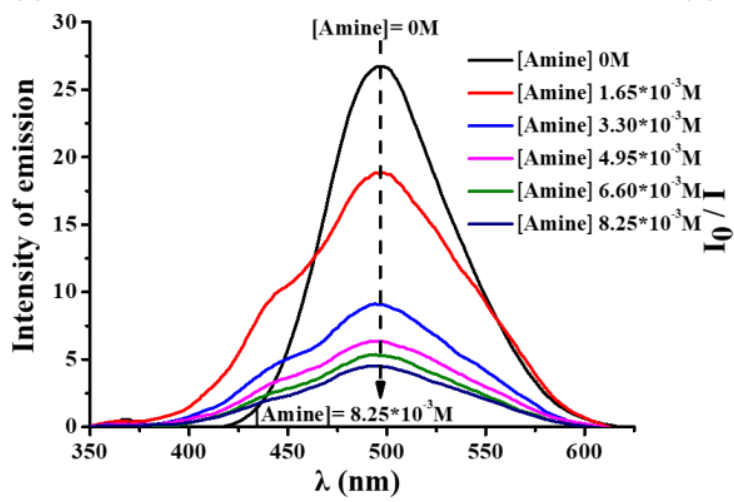

(b)
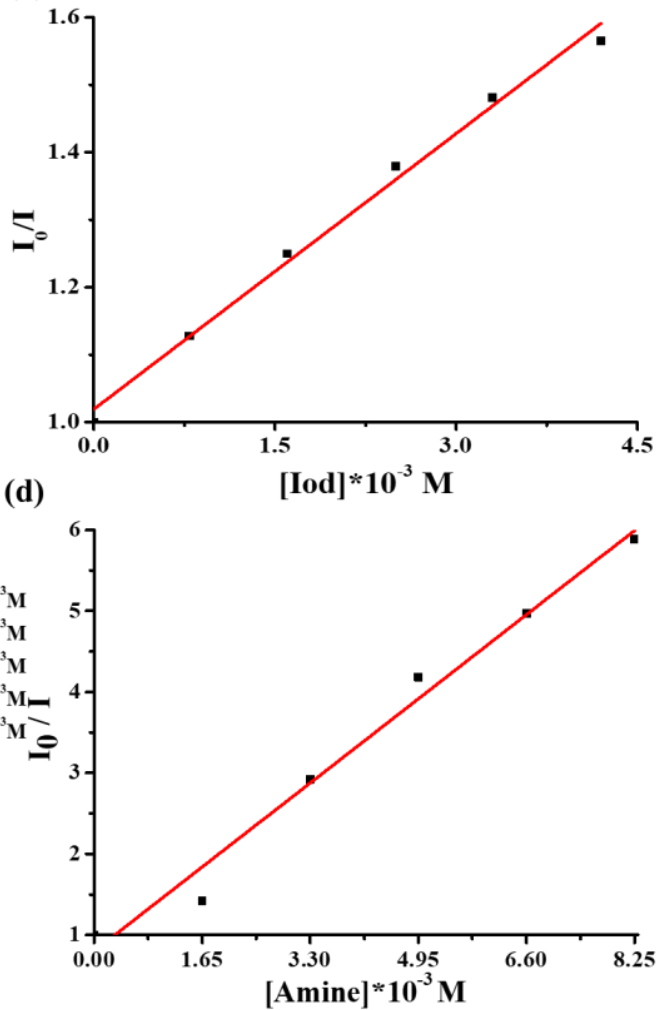

Figure 8. (a) Fluorescence quenching of bis-chalcone 9 by iodonium salt (speedcure 938); (b) Stern-Volmer treatment for the bis-chalcone 9/Iod fluorescence quenching; (c) Fluorescence quenching of bis-chalcone 9 by amine (speedcure EDB); (d) SternVolmer treatment for the bis-chalcone 9/EDB fluorescence quenching.

\subsubsection{Cyclic voltammetry to study electron transfer reaction for Bis-chalcones}

Cyclic voltammetry was also performed to study the relevant mechanism of bischalcones 5 and 9-based photoinitiating systems. As shown in Figure S2, a favorable electron transfer reaction occurred in bis-chalcone / iodonium salt: $\Delta \mathrm{G}_{\mathrm{S} 1}{ }^{\mathrm{Iod}}=-1.67 \mathrm{eV}$ and $-0.78 \mathrm{eV}$ for bis-chalcones 5 and 9, respectively (Table 4). Remarkably, two oxidation peaks were observed in the positive potential range of bis-chalcone 5, corresponding to a further oxidation (not reversible) even at higher potentials [50]. In addition, clear reduction peaks were observed as the oxidation reactions, revealing electron transfer reactions also occurred in bis-chalcone / amine (e.g., $\Delta \mathrm{G}_{\mathrm{S} 1}{ }^{\mathrm{EDB}}=-0.72$ $\mathrm{eV}$ and $-0.41 \mathrm{eV}$ for bis-chalcones 5 and 9 respectively, Table 4). 


\begin{tabular}{|c|c|c|}
\hline & bis-chalcone 5 & bis-chalcone 9 \\
\hline$K_{s v}^{\text {Iod }}\left(M^{-1}\right)$ & 346 & 734 \\
\hline$\Phi_{\text {et }}^{\text {Iod }}$ & 0.91 & 0.96 \\
\hline$K_{s v}^{\text {Amine }}\left(M^{-1}\right)$ & 20 & 40 \\
\hline$\Phi_{\text {et }}{ }^{\text {Amine }}$ & 0.64 & 0.78 \\
\hline Es1 $(e V)$ & 3.04 & 2.83 \\
\hline $\mathbf{E}_{\mathbf{o x}}(\mathrm{eV})$ & 0.67 & 1.35 \\
\hline $\mathbf{E}_{\text {red }}(e V)$ & -1.32 & -1.42 \\
\hline$\Delta \mathbf{G}_{\text {Iod }}^{\mathbf{S 1}}$ & -1.67 & -0.78 \\
\hline$\Delta \mathbf{G}^{\mathrm{S1}}$ EDB & -0.72 & -0.41 \\
\hline
\end{tabular}

Table 4. Parameters characterizing the fluorescence properties of bis-chalcones 5 and 9 in acetonitrile: Interaction constant (Ksv) of bis-chalcone-Iod and bis-chalcone-EDB systems calculated by Stern-Volmer equation; electron transfer quantum yield $\left(\Phi^{\mathrm{et}}\right)$ of bis-chalcone/Iod and bis-chalcone/EDB interactions; singlet excited state energy $\left(\mathrm{E}_{\mathrm{S} 1}\right)$; oxidation potential $\left(\mathrm{E}_{\mathrm{ox}}\right)$ and reduction potential $\left(\mathrm{E}_{\mathrm{red}}\right)$ measured by Cyclic Voltammetry experiments as well as free energy change of singlet electrode $\left(\Delta \mathrm{G}_{\mathrm{S} 1}\right)$.

\subsubsection{ESR experiments of bis-chalcones-based photoinitiating system}

The different generated radicals were detected by the ESR-spin trapping experiments on bis-chalcone 9/ iodonium salt and bis-chalcone 9/amine solutions under $\mathrm{N}_{2}$ in the presence of $N$-phenyl-tert-butyl nitrone (PBN) as the spin trap agent. As shown in the Figure 9 (a) and (b), in the presence of Iod, the PBN/aryl radical adducts were clearly observed $\left(\mathrm{a}_{\mathrm{N}}=14.4 \mathrm{G}\right.$ and $\mathrm{a}_{\mathrm{H}}=2.2 \mathrm{G}$, in full agreement with literature data [51]) showing that $\mathrm{r} 2$ occurs. While for the bis-chalcone/amine system (Figure 9 (c) and (d)), the hyperfine coupling constants for nitrogen and hydrogen were characterized by $\mathrm{a}_{\mathrm{N}}=14.4 \mathrm{G}$ and $\mathrm{a}_{\mathrm{H}}=2.2 \mathrm{G}$ that evidenced the generation of an 
aminoalkyl radical (r3) according to experimental data published elsewhere $\left(\mathrm{a}_{\mathrm{N}}=14.4\right.$ $\mathrm{G}$ and $\left.\mathrm{a}_{\mathrm{H}}=2.2 \mathrm{G},[52]\right)$.

(a)

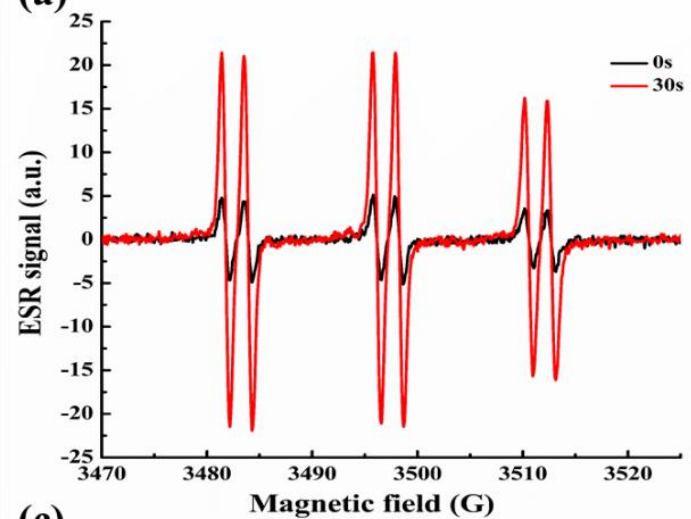

(c)

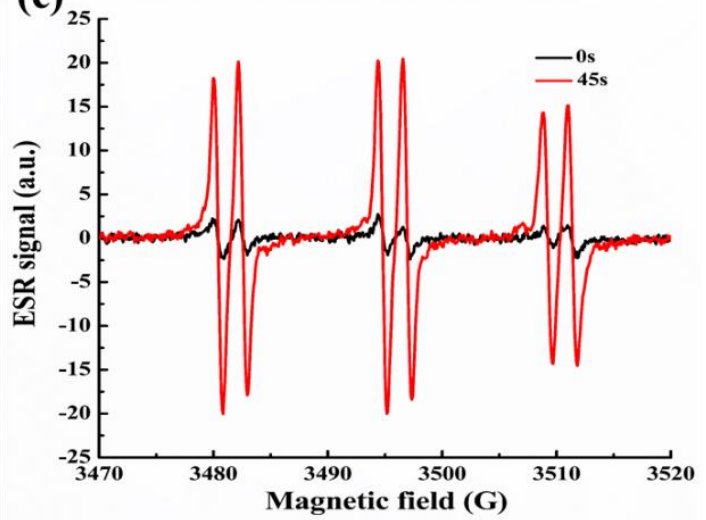

(b)

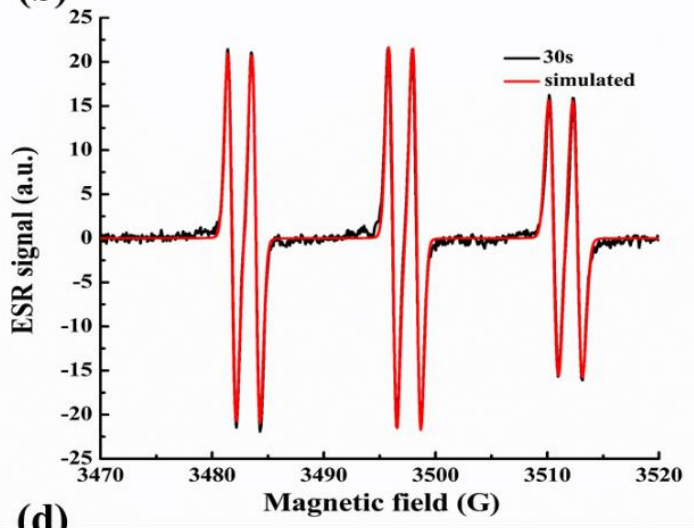

(d)

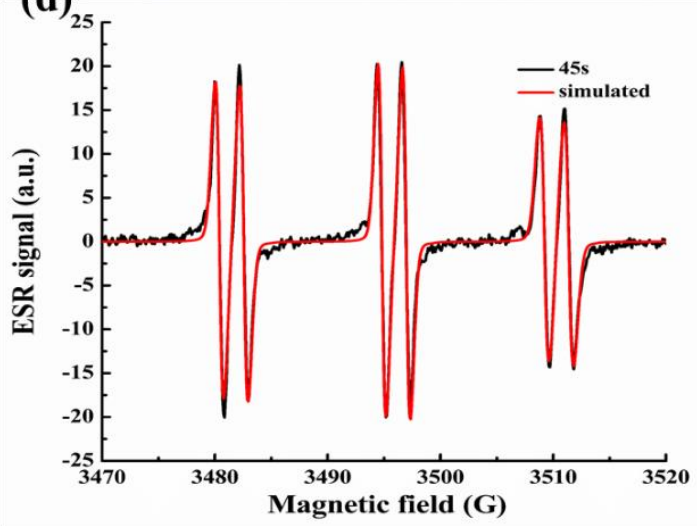

Figure 9. ESR spectra obtained from ESR-spin trapping experiment using $\mathrm{PBN}=2$ $\mathrm{mg} / \mathrm{mL}$ (as spin trap agent); iodonium salt (Speedcure 938) $=12.6 \mathrm{mg} / \mathrm{mL}$; amine $($ Speedcure $\mathrm{EDB})=12.6 \mathrm{mg} / \mathrm{mL}$ and bis-chalcone $9=0.8 \mathrm{mg} / \mathrm{mL}$ in acetonitrile under $\mathrm{N}_{2}$. (a) bis-chalcone 9/iodonium salt Irradiation time $=0 \mathrm{~s}$ (black) and $=30 \mathrm{~s}$ (red) spectra; (b) bis-chalcone 9/iodonium salt Irradiation time $=30 \mathrm{~s}$ (black) and simulated (red) spectra; (c) bis-chalcone 9/amine Irradiation time $=0 \mathrm{~s}$ (black) and $=45 \mathrm{~s}$ (red) spectra; (d) bis-chalcone 9/amine Irradiation time $=45 \mathrm{~s}$ (black) and simulated (red) spectra.

\subsection{Applications in 4D Printing}

3.5.1 Swelling experiment of PEG-polymers initiated by the proposed bis-chalcones based three-component PISs 
The swelling ratios of the PEG-polymers initiated by the three-component PISs based on bis-chalcones 5 or 9/Iod/amine $(1.5 \% / 1.5 \% / 1.5 \%, \mathrm{w} / \mathrm{w} / \mathrm{w})$ were investigated. As shown in Figure 10, after immersing in water to reach the swelling equilibrium, the swelling ratio of them were about $60 \%-70 \%$, and the volumes of them increased about $130 \%-160 \%$ (see in Table 5) than its primary. After that, they returned to its initial appearance and volume after heating at $50^{\circ} \mathrm{C}$ for $1 \mathrm{~h}$ to remove the water contained in the PEG-polymers, indicating that the swelling of these polymers is reversible.

(a)

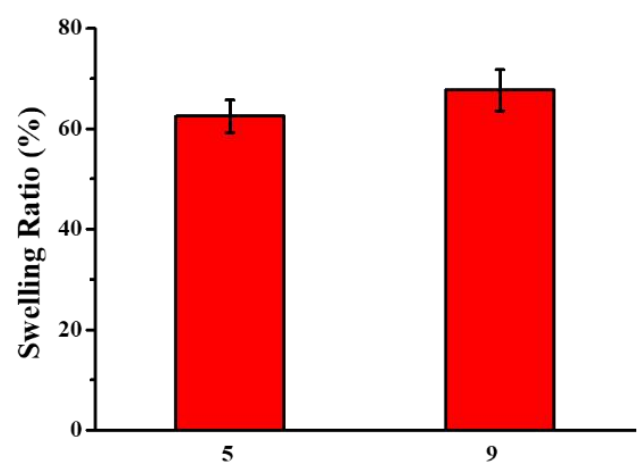

(b)

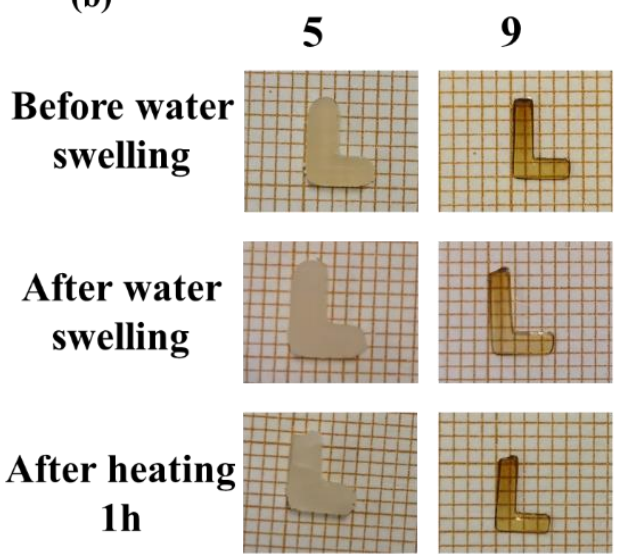

Figure 10. (a) the swelling ratio of PEG-polymer prepared using bis-chalcones as photoinitiators; (b) the photos of PEG-polymer initiated by bis-chalcone/Iod/amine before water swelling, after water swelling for $24 \mathrm{~h}$ and after heating for $1 \mathrm{~h}$ to remove water.

\begin{tabular}{|c|c|c|}
\hline & bis-chalcone 5 & bis-chalcone 9 \\
\hline $\mathbf{V}_{\mathbf{1}}\left(\mathbf{m m}^{\mathbf{3}}\right)$ & 31.11 & 17.97 \\
\hline $\mathbf{V}_{\mathbf{2}}\left(\mathbf{m m}^{\mathbf{3}}\right)$ & 49.60 & 24.06 \\
\hline $\mathbf{V}_{\mathbf{3}}\left(\mathbf{m m}^{\mathbf{3}}\right)$ & 30.40 & 16.28 \\
\hline $\boldsymbol{R}(\boldsymbol{\%})$ & $160 \%$ & $134 \%$ \\
\hline
\end{tabular}

Table 5. The 3D pattern volume for the comparison in the cycle: before water swelling $\left(\mathrm{V}_{1}\right)$, after water swelling $\left(\mathrm{V}_{2}\right)$, after heating $\left(\mathrm{V}_{3}\right)$ as well as the increase rate of volume after swelling $(R)$. 
3.5.2 The reversible deformation effect of PEG-polymer initiated by bischalcone/Iod/amine via swelling and dehydration induced actuation

Due to the high biocompatibility and hydrophilicity of prepared PEG-polymers, the novel proposed three-compound PIS combined with PEG-diacrylate is suitable for 3D bioprinting [53-54]. In addition, 3D printed hydrogels with spatial resolution characteristics induced by the proposed PISs are used to investigate the shape-memory via thermos-responsive and water-responsive processes [55-57]. Since the mechanical properties of PEG-diacrylate were related to the exposure time, different irradiation times were studied and the optimal one was selected. As shown in Figure 11(a), a cross shaped object with spatially resolved properties was designed (see Figure 11(a)-1) and obtained (see Figure 11(a)-2) through exposing the system based on bis-chalcone 5 upon LED@375nm for 20s (see Figure 13(b)). Then, the cross was soaked in a water filled beaker, and we can observe that it started to deform as the water swells, resulting in a completely curved cross (that is, the degree change was close to $180^{\circ}$ ) after swelling in water for 30s (Figure 11(a)-3 and SI Video 1). Subsequently, the cross was removed from water and heated at $100{ }^{\circ} \mathrm{C}$ to induce evaporation. Correspondingly, the curled cross flattened out and returned to its original shape after $100 \mathrm{~s}$ as the contained water was removed (Figure 11(a)-4 and SI Video 1). Then the continuous heating at $100{ }^{\circ} \mathrm{C}$ for 10 minutes to completely dehydrate the cross, it curled upside down as shown in Figure 11(a)-5. Finally, the cross was removed from oven at $100{ }^{\circ} \mathrm{C}$ to room temperature for $10 \mathrm{~min}$, the curled one was gradually flatten out or even returned to its primary shape (see Figure 11(a)-6). Compared with the system based on bis-chalcone 5, as the polymerization efficiency of that based on bis-chalcone 9 is lower, a cross based on bischalcone 9 was only obtain by exposing for 60s (Figure 11(b)-1-2). Furthermore, it's clearly shown in Figure 11(b)-2-6 and SI Video 2 that a complete shape-memory process can also be observed for the PEG-polymer based on bis-chalcone 9 via swelling in water for $40 \mathrm{~s}$ and dehydration in oven about $100{ }^{\circ} \mathrm{C}$ for $12 \mathrm{~min}$, which demonstrated that the available hydrogels initiated by the new PIS based on bis-chalcones/Iod/amine had a reversible deformation effect due to its thermal and water responsiveness of PEG. 
(a)
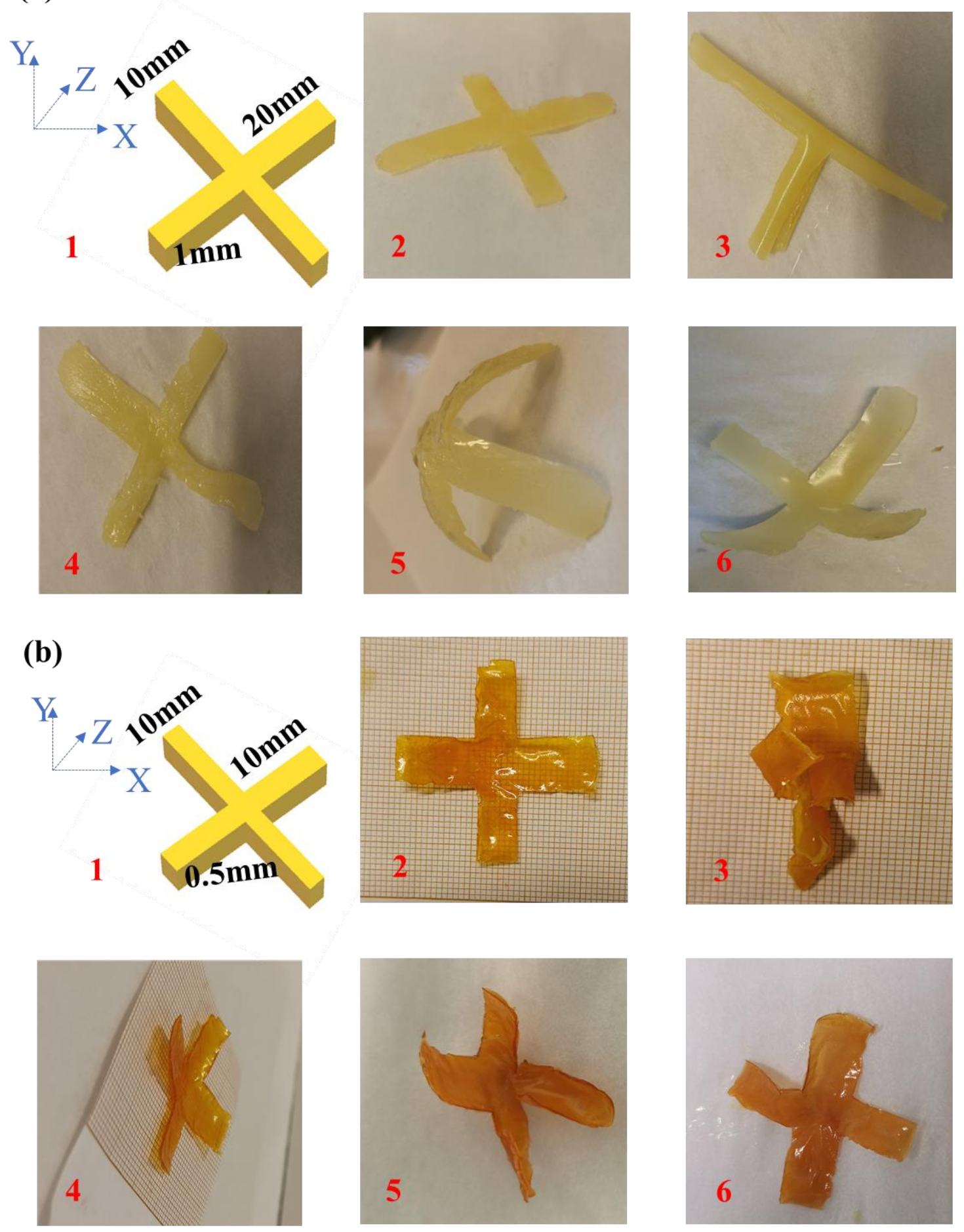

Figure 11. (a) Swelling and dehydration induced actuation of PEG-polymer initiated by bis-chalcone 5/Iod/amine irradiation with LED@375 nm: (1) the designed geometrical of cross, (2) cross of PEG-polymer after 1min light irridiation, (3) cross after water swelling for 1 min (see SI Video 1), (4) cross after 100 seconds of dehydration (heating at $100{ }^{\circ} \mathrm{C}$, see SI Video 1), (5) cross after 10 mins of dehydration (heating at $100{ }^{\circ} \mathrm{C}$ ), (6) cross after stay at room temperature for 10 mins; (b) Swelling 
and dehydration induced actuation of PEG-polymer initiated by bis-chalcone 9/Iod/amine irradiation with LED@375 nm: (1)the designed geometrical of cross, (2) cross of PEG-polymer after 1min light irridiation, (3) cross after water swelling for 1 min (see SI Video 2), (4) cross after 100 seconds of dehydration (heating at $100{ }^{\circ} \mathrm{C}$, see SI Video 2), (5) cross after 10 mins of dehydration (heating at $100{ }^{\circ} \mathrm{C}$ ), (6) cross after stay at room temperature for 10 mins.

\section{Conclusions}

In conclusion, ten different novel dyes (bis-chalcone derivatives) were synthesized and characterized as photoinitiators of polymerization. All the compounds displayed a strong absorption in the near UV or visible range due to the $\pi$-conjugation in the molecular structures, and the PISs based on the proposed dyes showed good efficiency for the free radical polymerization of acrylates under LEDs@405nm and LEDs@375nm, and the cationic polymerization of EPOX under LEDs@375nm. Remarkably, bis-chalcones 5 and 9 proved to be the excellent photoinitiators. The involved photochemical mechanisms of the proposed PISs were characterized by steady state photolysis, fluorescence quenching as well as ESR-ST experiments. Finally, by using the newly proposed three-component PISs for 3D printing experiments, a nice 3D pattern with good spatial resolutions was obtained. Simultaneously, the PEG-polymers exhibited an excellent thermoresponsive and water-responsive shape-memory effect. This work proves that the synthesized bis-chalcone derivatives can act as photoinitiators and their photopolymerization efficiency of PEG-diacrylate would increase with its conjugation effect, which corresponds to the different substituent groups and substitution positions. In addition, an environmentally friendly photocurable resin containing PEG-DA as the monomer, bis-chalcones used as photoinitiators in conjunction with an iodonium salt as co-initiator and an amine as the electron donor were successful achieved for application to 3D and 4D printing processes. Furthermore, the multi-stimulus-responsive shape-memory polymer network prepared by the above photocurable resin could be potentially applied for the design of biocompatible materials.

\section{Supplementary Materials:}

The following are available online 
Acknowledgments: This research project is supported by China Scholarship Council (CSC) 201906280059. The DGA is acknowledged for its financial support through the $\mathrm{PhD}$ grant of Damien Brunel. This research was also funded by the Agence Nationale de la Recherche (ANR agency) through the PhD grant of Guillaume Noirbent (ANR17-CE08-0054 VISICAT project). P. X. acknowledges funding from the Australian Research Council (FT170100301). This work was granted access to the HPC resources of the Mesocentre of the University of Strasbourg.

\section{Conflicts of Interest:}

The authors declare no conflict of interest.

\section{References}

[1] Ian, G., David, W. R, Brent, S. Photopolymerization processes. Additive Manufacturing Technologies. 2010.

[2] Lalevee, J., Fouassier, J.P. Photopolymerisation initiating systems. The Royal Society of Chemistry, London. 2018, 586.

[3] Fouassier, J.P.; Lalevée, J. Photoinitiators for polymer synthesis-scope, reactivity, and efficiency; Wiley-VCH Verlag GmbH \& Co. KGaA: Weinheim, Germany. 2012. [4] Junkers, T.; Laun. J. Controlled reversible deactivation radical photopolymerization, in photoinitiating systems, J Lalevée, J.P. Fouassier, Eds., Materials and Polymer Book Series, RSC, London. 2018, 29, 243-273.

[5] Xiao, P.; Zhang, J.; Dumur, F.; Tehfe, M. A.; Morlet-Savary, F.; Graff, B.; Gigmes, D.; Fouassier, J. P.; Lalevée, J. Visible light sensitive photoinitiating systems: Recent progress in cationic and radical photopolymerization reactions under soft conditions. Progress Polymer Science. 2015, 41, 32-66.

[6] Rahal, M.; Abdallah, M.; Bui, T.T.; Goubard, F.; Graff, B.; Dumur, F.; Toufaily, J.; Hamieh, T.; Lalevée, J. Design of new phenothiazine derivatives as visible light photoinitiators. Polymer Chemistry. 2020, 11, 3349-3359.

[7] Zhang, T.; Jiang, B.; Huang, Y.D. Combined use of methacrylate/epoxy functionalized silanes for tuning of hyperbranched polysiloxane structure. Materials Chemistry and Physics. 2020, 123525. 
[8] Zhang, J.; Hill, N.; Lalevee, J.; Fouassier, J.-P.; Zhao, J.; Graff, B.; Schmidt, T.-W.; Kable, S.-H.; Stenzel, M.-H.; Coote, M.-L.; Xiao, P., Multihydroxy-anthraquinone derivatives as free radical and cationic photoinitiators of various photopolymerizations under green LED. Macromolecular Rapid Communications. 2018, 39, e1800172.

[9] Zhang, J.; Lalevée, J.; S. Hill, N.; Kiehl, J.; Zhu, D.; Cox, N.; Langley, J.; H. Stenzel, M.; L. Coote, M.; Xiao, P. Substituent effects on photoinitiation ability of monoaminoanthraquinone-based photoinitiating systems for free radical photopolymerization under LEDs. Macromolecular Rapid Communications. 2020, [10] Hermanna, A.; Burrb, D.; Landrya, V. Comparative study of the impact of additives against oxygen inhibition additives pendulum hardness and abrasion resistance for UV-curable wood finishes. Progress in Organic Coatings. 2020, 148, 105879.

[11] Lalevée, J.; Fouassier, J.P. Dyes and chomophores in polymer science, ISTE Wiley, London 2015.

[12] Abdallah, M.; Dumur, F.; Graff, B.; Hijazi, A.; Lalevée, J. High performance dyes based on triphenylamine, cinnamaldehyde and indane-1,3-dione derivatives for blue light induced polymerization for 3D printing and photocomposites. Dyes and Pigments. 2020 ,

[13] Xiao, P.; Dumur, F.; Graff, B.; Gigmes, D.; Fouassier, J.-P.; Lalev é e, J. Blue light sensitive dyes for various photopolymerization reactions: Naphthalimide and naphthalic anhydride derivatives. Macromolecules. 2014, 47, 601-608.

[14] Lalevée, J.; Fouassier, J.P. Dye photosensitized polymerization reactions: novel perspectives. A. Albini, E. Fasani (Eds.), RSC photochemistry reports, Photochemistry, London, UK, 2015, 215-232

[15] Breloy, L.; Ouarabi, C.A.; Brosseau, A.; Dubot, P.; Brezova, V.; Andaloussi, S.A.; Malval, J.-P.; Versace, D.-L. $\beta$-Carotene/Limonene derivatives/eugenol: green synthesis of antibacterial coatings under visible-light exposure. ACS Sustainable Chemistry Engineering. 2019, 7(24), 19591-19604. 
[16] Barrales-Rienda, J.M.; Brown, G.R.; Pepper, D.C. Cationic and free radical propagation of copolymerization by the $\mathrm{N}$-vinyl carbazole cation-radical. Polymer. $1969,10,327-332$.

[17] Ding, Y.; Padias, A.B.; Hall Jr, H.K. Chemical trapping experiments support a cation-radical mechanism for the oxidative polymerization of aniline. Journal of Polymer Science-Part A: Polymer Chemistry. 1999, 37(14), 2569-2579.

[18] El-Roz, M.; Lalevée, J.; Morlet-Savary, F.; Allonas, X.; Fouassier, J.-P. Coinitiators based on group 14 elements in photoinitiating systems for radical and cationic polymerization. Macromolecules. 2009, 42, 4464-4469.

[19] Rammohan, A.; Reddy, J.S.; Sravya, G.; Rao, C.N.; Zyryanov, G.V. Chalcone synthesis, properties and medicinal applications: a review. Environmental Chemistry Letters. 2020, 18, 433-458.

[20] Son, K. I.; Kang, S. Y.; Noh, D. Y., Electrochemical and fluorescent properties of ferrocenyl-chalcone with N-Ethyl carbazole group. Bulletin of the Korean Chemical Society. 2009, 30(2), 513-516.

[21] Nechifor, M. Novel chalcone-based aromatic polyamides: synthesis, characterization, and properties. Designed Monomers and Polymers. 2016, 19(2), 161171.

[22] Urano, T.; Nagao, T.; Takada, A.; Itoh, H. Photosensitization Mechanisms in Photopolymer Coating Film Containing Photoinitiators Sensitized by Aminochalconetype Dye for Computer- to-photopolymer Plate. Polymers for Advanced Technologies. $1999,10,244-250$.

[23] Chen, H.; Noirbent, G.; Sun, K.; Brunel, D.; Gigmes, D.; Morlet-Savary, F.; Zhang, Y.J.; Liu, S.H.; Xiao, P.; Dumur, F.; Lalevée, J. Photoinitiators derived from natural product scaffolds: monochalcones in three-component photoinitiating systems and their applications in 3D printing. Polymer Chemistry. 2020, 11, 4647-4659.

[24] Tehfe, M. A.; Dumur, F.; Xiao, P.; Delgove, M.; Graff, B.; Fouassier, J. P.; Didier Gigmes, D.; Lalevée, J. Chalcone derivatives as highly versatile photoinitiators for radical, cationic, thiol-ene and IPN polymerization reactions upon exposure to visible light. Polymer Chemistey. 2014, 5, 382-390. 
[25] Chen, H.; Noirbent, G.; Zhang, Y.J.; Brunel, D.; Gigmes, D.; Liu, S.H.; Sun, K.; Morlet-Savary, F.; Graff, B.; Xiao, P.; Dumur, F.; Lalevée, J. Novel D- $\pi$-A and A- $\pi$-D$\pi$-A Three-Component Photoinitiating Systems Based on Carbazole/Triphenylamino based Chalcones and Application in 3D/4D Printing.

[26] Xu, Y.Y.; Guillaume Noirbent,G.; Brunel, D.; Ding, Z.F.; Didier Gigmes, D.; Graff, B.; Xiao, P.; Dumur, F.; Lalevée, J. Novel ketone derivative-based photoinitiating systems for free radical polymerization under mild conditions and 3D printing. Polymer Chemistey. 2020, Advance Article.

[27] Lendlein, A.; Kelch, S. Shape-memory polymers. Angewandte Chemie International Edition. 2002, 41, 2034-2057.

[28] Ratna, D.; Karger-Kocsis, J. Recent Advances in Shape Memory Polymers and Composites: A Review. Journal of Materials Science. 2008, 43, 254-269.

[29] Zheng, X. T.; Zhou, S. B.; Li, X. H.; Weng, J. Shape memory properties of poly( D , L -Lactide)/hydroxyapatite composites. Biomaterials. 2006, 27, 4288-4295.

[30] Lendlein, A.; Jiang, H.; Jünger, O.; Langer, R. Light-induced shape-memory polymers. Nature. $2005,434,879-882$.

[31] Liu, Y.; Lv, H.; Lan, X.; Leng, J.; Du, S. Review of electro-active shape-memory polymer composite. Composites Science and Technology. 2009, 69, 2064-2068.

[32] Zheng, X. T.; Zhou, S. B.; Xiao, Y.; Yu, X. J.; Li, X. H.; Wu, P. Z. Shape memory effect of poly( D , L -Lactide)/Fe3O4 nanocomposites by inductive heating of magnetite particles. Colloids and Surfaces B: Biointerfaces. 2009, 71, 67-72.

[33] Chen, S.; Hu, J.; Yuen, C.-w.; Chan, L. Novel moisture-sensitive shape memory polyurethanes containing pyridine moieties. Polymer. 2009, 50, 4424-4428.

[34] Chen, S.; Hu, J.; Zhuo, H. Study on the moisture absorption of pyridine containing polyurethane for moisture-responsive shape memory effects. Journal of Materials Science. 2011, 46, 6581-6588.

[35] Lendlein, A.; Langer, R. Biodegradable, elastic shape-memory polymers for potential biomedical applications. Science 2002, 296, 1673-1676.

[36] Yu, X. J.; Wang, L.; Huang, M. T.; Gong, T.; Li, W. B.; Cao, Y. L.; Ji, D. J.; Wang, P.; Wang, J.; Zhou, S. B. A Shape memory stent of poly( $\varepsilon$-caprolactone-co- DL -lactide) 
copolymer for potential treatment of esophageal stenosis. Journal of Materials Science: Materials in Medicine. 2012, 23, 581-589.

[37] Liu, X.;Zhao, K.;Gong,T.;Song, J.; Bao,C. Y.;Luo, E.; Weng, J.; Zhou, S. B. Delivery of Growth Factors Using a Smart Porous Nanocomposite Scaffold to Repair a Mandibular Bone Defect. Biomacromolecules. 2014, 15, 1019-1030.

[38] Wischke, C.; Neffe, A. T.; Steuer, S.; Lendlein, A. Evaluation of a Degradable Shape-Memory Polymer Network as Matrix for Controlled Drug Release. J. Controlled Release. 2009, 138, 243-250.

[39] Abdallah, M.; Magaldi, D.; Hijazi, A.; Graff, B.; Dumur, F.; Fouassier, J. P.; Bui, T. T.; Goubard, F.; Lalevée, J., Development of new high-performance visible light photoinitiators based on carbazole scaffold and their applications in $3 \mathrm{~d}$ printing and photocomposite synthesis. Journal of Polymer Science Part A: Polymer Chemistry 2019, 57 (20), 2081-2092.

[40] Yang, H.J.; J.Bard, A. The application of rapid scan cyclic voltammetry and digital simulation to the study of the mechanism of diphenylamine oxidation, radical cation dimerization, and polymerization in acetonitrile. Journal of Electroanalytical Chemistry and Interfacial Electrochemistry. 1991, 306, 87-109.

[41] Sun, K.; Xu, Y. Y.; Dumur, F.; Morlet-Savary, F.; Hong Chen, H.; Céline Dietlin, C.; Graff, B.; Lalevee, J.; Xiao, P., In silico rational design by molecular modeling of new ketones as photoinitiators in three-component photoinitiating systems: application in 3D printing. Polymer Chemistry. 2020,11(12), 2230-2242.

[42] Duling, D.R. Simulation of multiple isotropic spin-trap EPR spectra. Journal of Magnetic Resonance. 1994, 104, 105-110.

[43] Zhang, Y.J.; Chen, H.; Zhang, T.T.; Zan, Y.; Ni, T.Y.; Liu, M.; Pei, R.J. Fastforming BMSC-encapsulating hydrogels through bioorthogonal reaction for osteogenic differentiation. Biomaterial Science. 2018, 6, 2578-2581.

[44] Chen, H.; Zhang, Y.J.; Ding, P.; Zhang, T.T.; Zan, Y.; Ni, T.Y.; Lin, R.; Liu, M.; Pei, R.J. Effective vascularization of BMSCs encapsulated in functionalized gellan gum/collagen hydrogel. ACS Applied Bio Materials, 2018, 1(5), 1408-1415. 
[45] Liu, Y.; Li, Y.; Yang, G.; Zheng, X. T.; Zhou, S. B. Multi-stimulus-responsive shape-memory polymer nanocomposite network cross-linked by cellulose nanocrystals. ACS Applied Materials \& Interfaces. 2015, 7 (7), 4118-4126.

[46] H. Saikachi, H. Muto, Preparation of resonance-stabilized bisphosphoranes, Chemical \& Pharmaceutical Bulletin (1971), 19, (11), 2262-70

[47] E. C. Constable, R. Martinez-Maiiez, A. M. W. Cargill Thompsonar, j. V. Walker, Metallosupramolecular Complexes containing Ferrocenyl Groups as Redox Spectators; Synthesis and Co-ordination Behaviour of the Helicand 4',4“"-Bis(ferroceny1)2,2‘:6',2”:6”,2”:6”, 2",',-quinquepyridine, J. Chem. Soc. Dalton Trans. (1994) 1585

[48] Corakci, B.; O. Hacioglu, S.; Toppare, L.; Bulut, U. Long wavelength photosensitizers in photoinitiated cationic polymerization: the effect of quinoxaline derivatives on photopolymerization. Ploymer. 2013, 54, 3182-3187.

[49] Crivello, J.V.; Lam, J.H.W. Ścigalski, F.; Jędrzejewska, B. Dye-sensitized photoinitiated cationic polymerization. Journal of Polymer Science: Polymer Chemistry Edition. 1978, 16(10), 2441-2451.

[50] Da Costa, R.; Farias, F.; Maqueira, L.; Castanho Neto, C.; Carneiro, L.; Almeida, J.; Buarque, C.; Aucélio, R.; Limberger, J., Synthesis, photophysical and electrochemical properties of novel D- $\pi$-D and D- $\pi$-A triphenylamino-chalcones and $\beta$ arylchalcones. Journal of the Brazilian Chemical Society. 2019, 30(1), 81-89.

[51] Tehfe, M.-A.; Lalevée, J.; Morlet-Savary, F.; Graff, B.; Blanchard, N.; Fouassier, J.-P. Blue light sensitive dyes for various photopolymerization reactions: naphthalimide and naphthalic and naphthalic anhydride derivetives. ACS. Macro. Lett. 2012, 1, 198203.

[52] Zhang, J.; Wang, S.H.; Lalevée, J.; Morlet-Savary, F.; Lam, E.S.H.; Graff, B.; Liu, J.; Xing, F.Y.; Xiao, P. 1,2-Diketones as Photoinitiators of both cationic and freeradical photopolymerization under UV (392 nm) or Blue (455 nm) LEDs. J. Polym. Sci. $2020,58,792-802$.

[53] M.Cruise, G.; S.Scharp, D.; A.Hubbella, J. Characterization of permeability and network structure of interfacially photopolymerized poly(ethylene glycol) diacrylate hydrogels. Biomaterials, 1998, 19(14), 1287-1294. 
[54] Rukmani, S.J.; Anstine, D.M.; Munasinghe, A.; Colina. C.M. An insight into structural and mechanical properties of ideal-networked poly (ethylene glycol)-peptide hydrogels from molecular dynamics simulations. Macromolecular Chemistry and Physics. 2020, 221(3), 1900326.

[55] Pawar, A. A.; Halivni, S.; Waiskopf, N.; Ben-Shahar, Y.; Soreni-Harari, M.; Bergbreiter, S.; Banin, U.; Magdassi, S. Rapid three-dimensional printing in water using semiconductor-metal hybrid nanoparticles as photoinitiators. Nano Letters. 2017; 17 (7), 4497-4501.

[56] Niu, J.; Lunn, D. J.; Pusuluri, A.; Yoo, J. I.; OQMalley, M. A.; Mitragotri, S.; Soh, H. T.; Hawker, C. J. Engineering live cell surfaces with functional polymers via cytocompatible controlled radical polymerization. Nature Chemistry. 2017, 9, 537.

[57] Zhang, Z. H.; Corrigan, N.; Bagheri, A.; Jin, J. Y.; Boyer, C. A versatile 3D and 4D printing system through photocontrolled RAFT polymerization. Angewandte Chemie. 2019, 131, 18122-18131. 



\section{Supplementary Information}

\section{Bis-Chalcone Derivatives Derived from Natural Products as Near- UV/Visible Light Sensitive Photoinitiators for 3D/4D Printing}

Hong Chen ${ }^{1,2}$, Guillaume Noirbent ${ }^{3}$, Shaohui Liu ${ }^{1,2}$, Damien Brunel ${ }^{3}$, Bernadette Graff $^{1,2}$, Didier Gigmes ${ }^{3}$, Yijun Zhang ${ }^{1,2}$, Ke Sun ${ }^{1,2}$, Fabrice Morlet-Savary ${ }^{1,2}$, Pu Xiao $^{4 *}$, Frédéric Dumur ${ }^{3 *}$, Jacques Lalevée ${ }^{1,2^{*}}$

1 Institut de Science des Matériaux de Mulhouse, IS2M-UMR CNRS 7361, UHA, 15, rue Jean Starcky, Cedex 68057 Mulhouse, France ; jacques.lalevee@uha.fr

2 Université de Strasbourg, France; jacques.lalevee@uha.fr

3 Aix Marseille Univ, CNRS, ICR UMR 7273, F-13397 Marseille, France ; frederic.dumur@univ-amu.fr

4 Research School of Chemistry, Australian National University, Camberra, ACT 2601, Australia; pu.xiao@anu.edu.au

* Corresponding author: jacques.lalevee@uha.fr (J. L.), frederic.dumur@univ-amu.fr (F.D.); pu.xiao@anu.edu.au (P. X.). 
Figure S1. Contour plots of HOMOs and LUMOs for bis-chalcones 5 and 9 optimized at the B3LYP/6-31G* level of theory.
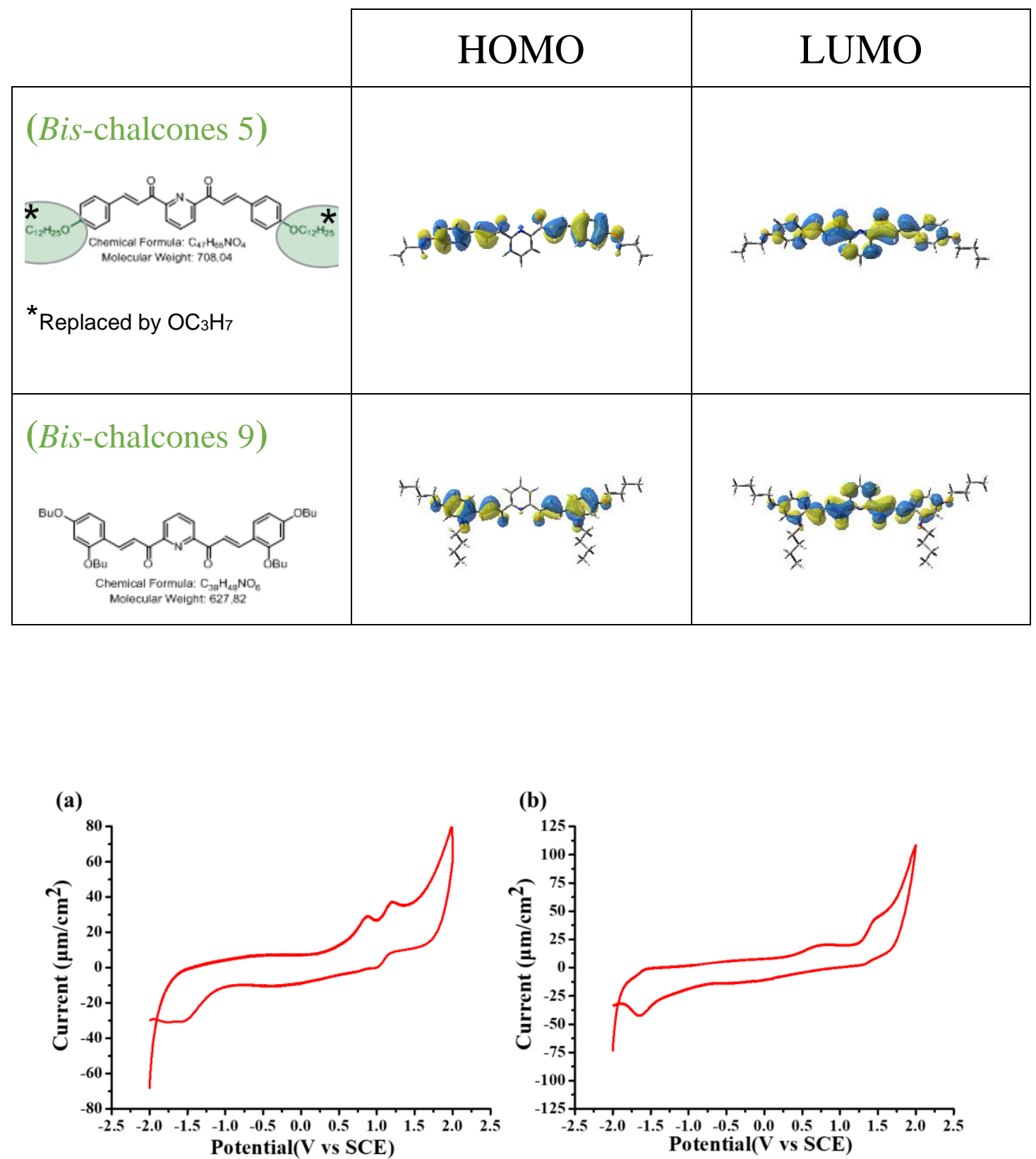

Figure S2. Cyclic voltammetry of electrochemical reactions of bis-chalcones 5 and 9 in acetonitrile solvent against saturated calomel electrode (SCE) under nitrogen saturated solution: (a) bis-chalcone 5; (b) bis-chalcone 9 . 



\section{Synthesis of the different bis-chalcones}

All reagents and solvents were purchased from Aldrich or Alfa Aesar and used as received without further purification. Mass spectroscopy was performed by the Spectropole of Aix-Marseille University. ESI mass spectral analyses were recorded with a 3200 QTRAP (Applied Biosystems SCIEX) mass spectrometer. The HRMS mass spectral analysis was performed with a QStar Elite (Applied Biosystems SCIEX) mass spectrometer. Elemental analyses were recorded with a Thermo Finnigan EA 1112 elemental analysis apparatus driven by the Eager 300 software. 1H and 13C NMR spectra were determined at room temperature in $5 \mathrm{~mm}$ o.d. tubes on a Bruker Avance 400 spectrometer of the Spectropole: $1 \mathrm{H}(400 \mathrm{MHz})$ and $13 \mathrm{C}(100 \mathrm{MHz})$. The $1 \mathrm{H}$ chemical shifts were referenced to the solvent peaks: DMSO (2.49 ppm), $\mathrm{CDCl} 3$ (7.26 $\mathrm{ppm})$ and the $13 \mathrm{C}$ chemical shifts were referenced to the solvent peaks: DMSO (49.5 ppm), $\mathrm{CDCl} 3(77.0 \mathrm{ppm})$, respectively. All photoinitiators were prepared with analytical purity up to accepted standards for new organic compounds (>98\%), which were checked by high field NMR analysis.

Synthesis of 1-benzyl-3,5-bis((E)-2,4-bis(allyloxy)benzylidene)piperidin-4-one (bischalcone 1)

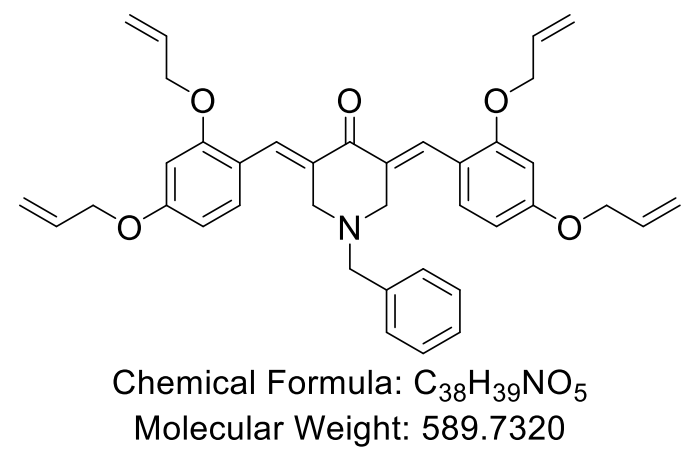

2,4-Bis(allyloxy)benzaldehyde (4.36 g, $20 \mathrm{mmol}, \mathrm{M}=218.25 \mathrm{~g} / \mathrm{mol}$ ) and 1benzylpiperidin-4-one (1.89 g, $10 \mathrm{mmol}, \mathrm{M}=189.26 \mathrm{~g} / \mathrm{mol})$ were dissolved in ethanol $(50 \mathrm{~mL})$ and aq. $\mathrm{KOH}(40 \%)(15 \mathrm{~mL})$ was added. The solution was stirred at room temperature overnight. During reaction, a precipitate formed. It was filtered off, washed several times with ethanol and dried under vacuum. The resulting solid was dissolved in dichloromethane and the solution was filtered on a plug of $\mathrm{SiO} 2$ using dichloromethane as the eluent. The solvent was removed under reduced pressure. Dissolution in a minimum of dichloromethane followed by addition of pentane precipitated a solid that was filtered off, washed several times with pentane and dried under vacuum (4.48 g, 76\% yield). 1H NMR (300 MHz, CDCl3) $\delta 8.11$ (s, 2H), $7.24-$ $7.15(\mathrm{~m}, 5 \mathrm{H}), 7.04(\mathrm{~d}, \mathrm{~J}=8.4 \mathrm{~Hz}, 2 \mathrm{H}), 6.45(\mathrm{dt}, \mathrm{J}=8.4,2.3 \mathrm{~Hz}, 4 \mathrm{H}), 6.13-5.96(\mathrm{~m}$, $4 \mathrm{H}), 5.48-5.42(\mathrm{~m}, 2 \mathrm{H}), 5.42-5.36(\mathrm{~m}, 2 \mathrm{H}), 5.33-5.30(\mathrm{~m}, 2 \mathrm{H}), 5.29-5.26(\mathrm{~m}$, 2H), $4.55(\mathrm{~m}, 8 \mathrm{H}), 3.80(\mathrm{~s}, 4 \mathrm{H}), 3.66(\mathrm{~s}, 2 \mathrm{H}) .13 \mathrm{C} \mathrm{NMR}(75 \mathrm{MHz}, \mathrm{CDCl} 3) \delta 160.76$, 
159.02, 133.03, 132.99, 131.34, 129.21, 128.30, 127.25, 118.11, 117.85, 105.58, 100.37, 69.34, 69.05, 31.03; HRMS (ESI MS) m/z: theor: 590.2901 found: 590.2904 $([\mathrm{M}+\mathrm{H}]+$ detected $)$.

Synthesis of 1-benzyl-3,5-bis((E)-2,4-dibutoxybenzylidene)piperidin-4-one (bischalcone 2)<smiles>CCOc1ccc(/C=C2/CN(Cc3cccc(OC(C)(C)C)c3OCC)C/C(=C\c3ccc(OC(C)(C)C)cc3OCC)C2=O)cc1</smiles>

2,4-Butoxybenzaldehyde ( $5.00 \mathrm{~g}, 20 \mathrm{mmol}, \mathrm{M}=250.34 \mathrm{~g} / \mathrm{mol}$ ) and 1-benzylpiperidin4-one $(1.89 \mathrm{~g}, 10 \mathrm{mmol}, \mathrm{M}=189.26 \mathrm{~g} / \mathrm{mol})$ were dissolved in ethanol $(50 \mathrm{~mL})$ and aq. $\mathrm{KOH}(40 \%)(15 \mathrm{~mL})$ was added. The solution was stirred at room temperature overnight. During reaction, a precipitate formed. It was filtered off, washed several times with ethanol and dried under vacuum. The resulting solid was dissolved in dichloromethane and the solution was filtered on a plug of $\mathrm{SiO} 2$ using dichloromethane as the eluent. The solvent was removed under reduced pressure. Dissolution in a minimum of dichloromethane followed by addition of pentane precipitated a solid that was filtered off, washed several times with pentane and dried under vacuum $(5.75 \mathrm{~g}$, $88 \%$ yield). 1H NMR (400 MHz, CDCl3) $\delta 8.11(\mathrm{~s}, 2 \mathrm{H}), 7.25-7.15(\mathrm{~m}, 5 \mathrm{H}), 7.04(\mathrm{~d}$, $\mathrm{J}=8.5 \mathrm{~Hz}, 2 \mathrm{H}), 6.45(\mathrm{~d}, \mathrm{~J}=2.3 \mathrm{~Hz}, 2 \mathrm{H}), 6.41(\mathrm{dd}, \mathrm{J}=8.5,2.3 \mathrm{~Hz}, 2 \mathrm{H}), 3.98(\mathrm{td}, \mathrm{J}=$ $6.5,3.0 \mathrm{~Hz}, 8 \mathrm{H}), 3.80(\mathrm{~s}, 4 \mathrm{H}), 3.66(\mathrm{~s}, 2 \mathrm{H}), 1.87-1.73(\mathrm{~m}, 8 \mathrm{H}), 1.57-1.44(\mathrm{~m}, 8 \mathrm{H})$, 0.99 (t, J = 7.4 Hz, 12H). 13C NMR (101 MHz, CDCl3) $\delta 187.61,161.42,159.69$, 137.92, 132.32, 131.32, 131.29, 129.18, 128.26, 127.16, 117.72, 104.92, 99.71, 68.37, $67.89,60.97,54.86,31.38,31.28,19.40,19.34,13.95,13.93$; HRMS (ESI MS) m/z: theor: 654.4153 found: $654.4150([\mathrm{M}+\mathrm{H}]+$ detected $)$.

Synthesis of 3,5-bis(ferrocenyle)tetrahydro-4H-thiopyran-4-one (bis-chalcone 3)

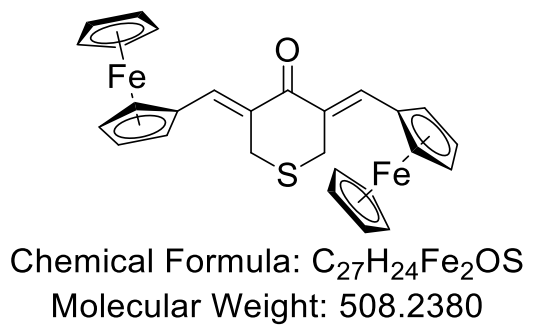

Ferrocenecarboxyaldehyde ( $3.68 \mathrm{~g}, 17.21 \mathrm{mmol}, \mathrm{M}=214.04 \mathrm{~g} / \mathrm{mol})$ ) and tetrahydro4H-thiopyran-4-one $(1.0 \mathrm{~g}, 8.61 \mathrm{mmol}, \mathrm{M}=116.18 \mathrm{~g} / \mathrm{mol})$ were dissolved in ethanol $(50 \mathrm{~mL})$ and aq. $\mathrm{KOH}(40 \%)(15 \mathrm{~mL})$ was added. The solution was stirred at room 
temperature overnight. During reaction, a precipitate formed. It was filtered off, washed several times with ethanol and dried under vacuum. The resulting solid was dissolved in dichloromethane and the solution was filtered on a plug of $\mathrm{SiO} 2$ using dichloromethane as the eluent. The solvent was removed under reduced pressure. Dissolution in a minimum of dichloromethane followed by addition of pentane precipitated a solid that was filtered off, washed several times with pentane and dried under vacuum (4 g, 91\% yield). 1H NMR (400 MHz, CDCl3) $\delta 7.57$ (s, 2H), 4.44 (s, 4H), 4.38 (s, 4H), 4.13 (s, 10H), 3.84 (s, 4H); 13C NMR (101 MHz, CDCl3) $\delta 137.4$, 78.7, 71.2, 71.0, 67.0, 53.5, 30.0; HRMS (ESI MS) m/z: theor: 509.0319 found: $509.0322([\mathrm{M}+\mathrm{H}]+$ detected $)$.

Synthesis of 3,5-bis((Z)-2,4-dibutoxybenzylidene)tetrahydro-4H-thiopyran-4-one (bischalcone 4)

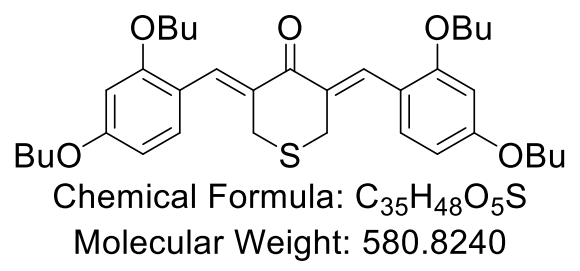

2,4-Butoxybenzaldehyde $(5.00 \mathrm{~g}, 20 \mathrm{mmol}, \mathrm{M}=250.34 \mathrm{~g} / \mathrm{mol})$ and tetrahydro-4Hthiopyran-4-one (1.16 g, $10 \mathrm{mmol}, \mathrm{M}=116.18 \mathrm{~g} / \mathrm{mol}$ ) were dissolved in ethanol (50 $\mathrm{mL})$ and aq. $\mathrm{KOH}(40 \%)(15 \mathrm{~mL})$ was added. The solution was stirred at room temperature overnight. During reaction, a precipitate formed. It was filtered off, washed several times with ethanol and dried under vacuum. The resulting solid was dissolved in dichloromethane and the solution was filtered on a plug of $\mathrm{SiO} 2$ using dichloromethane as the eluent. The solvent was removed under reduced pressure. Dissolution in a minimum of dichloromethane followed by addition of pentane precipitated a solid that was filtered off, washed several times with pentane and dried under vacuum (4.82 g, 83\% yield). 1H NMR (400 MHz, CDCl3) $\delta 7.92$ (s, 2H), 7.18 $(\mathrm{d}, \mathrm{J}=9.1 \mathrm{~Hz}, 2 \mathrm{H}), 6.51-6.45(\mathrm{~m}, 4 \mathrm{H}), 3.98(\mathrm{td}, \mathrm{J}=6.5,3.2 \mathrm{~Hz}, 8 \mathrm{H}), 3.84(\mathrm{~s}, 4 \mathrm{H})$, $1.86-1.74(\mathrm{~m}, 8 \mathrm{H}), 1.56-1.44(\mathrm{~m}, 8 \mathrm{H}), 0.98(\mathrm{td}, \mathrm{J}=7.4,4.0 \mathrm{~Hz}, 12 \mathrm{H}) .13 \mathrm{C}$ NMR (101 MHz, CDCl3) $\delta 189.23,161.51,159.54,132.88,132.58,131.47,117.56,105.01$, 99.96, 68.45, 68.01, 31.43, 31.32, 30.66, 19.43, 19.39, 13.99, 13.97; HRMS (ESI MS) $\mathrm{m} / \mathrm{z}$ : theor: 654.4153 found: $654.4150([\mathrm{M}+\mathrm{H}]+$ detected $)$.

Synthesis of (2E,2'E)-1,1'-(pyridine-2,6-diyl)bis(3-(4-(dodecyloxy)phenyl)prop-2-en1-one) (bis-chalcone 5) 


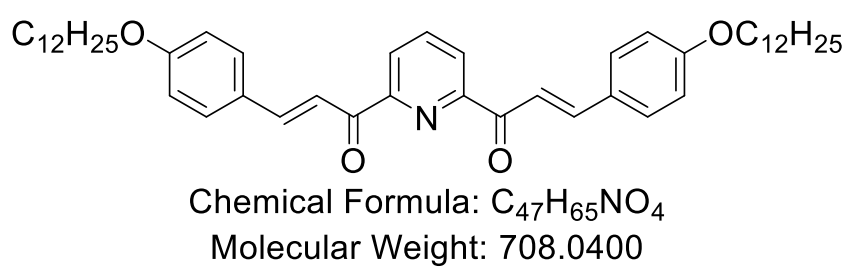

4-(Dodecyloxy)benzaldehyde (5.81 g, $20 \mathrm{mmol}, \mathrm{M}=290.45 \mathrm{~g} / \mathrm{mol}$ ) and 2,6diacetylpyridine ( $1.63 \mathrm{~g}, 10 \mathrm{mmol}, \mathrm{M}=163.18 \mathrm{~g} / \mathrm{mol}$ ) were dissolved in ethanol (50 $\mathrm{mL})$ and aq. $\mathrm{KOH}(40 \%)(15 \mathrm{~mL})$ was added. The solution was stirred at room temperature overnight. During reaction, a precipitate formed. It was filtered off, washed several times with ethanol and dried under vacuum. The resulting solid was dissolved in dichloromethane and the solution was filtered on a plug of $\mathrm{SiO} 2$ using dichloromethane as the eluent. The solvent was removed under reduced pressure. Dissolution in a minimum of dichloromethane followed by addition of pentane precipitated a solid that was filtered off, washed several times with pentane and dried under vacuum (5.73 g, 81\% yield). 1H NMR (400 MHz, CDCl3) $\delta 8.38-8.30(\mathrm{~m}, 4 \mathrm{H})$, $8.08-8.03(\mathrm{~m}, 1 \mathrm{H}), 8.00(\mathrm{dd}, \mathrm{J}=14.6,4.9 \mathrm{~Hz}, 2 \mathrm{H}), 7.71(\mathrm{~d}, \mathrm{~J}=8.7 \mathrm{~Hz}, 4 \mathrm{H}), 6.97(\mathrm{~d}$, $\mathrm{J}=8.8 \mathrm{~Hz}, 4 \mathrm{H}), 4.04(\mathrm{t}, \mathrm{J}=6.6 \mathrm{~Hz}, 4 \mathrm{H}), 1.88-1.78(\mathrm{~m}, 4 \mathrm{H}), 1.56-1.45(\mathrm{~m}, 4 \mathrm{H}), 1.44$ $-1.26(\mathrm{~m}, 32 \mathrm{H}), 0.90(\mathrm{t}, \mathrm{J}=6.8 \mathrm{~Hz}, 6 \mathrm{H}) .13 \mathrm{C} \mathrm{NMR}(101 \mathrm{MHz}, \mathrm{CDCl} 3) \delta 188.63$, 161.57, 153.37, 144.97, 138.18, 130.51, 127.75, 125.56, 118.36, 115.00, 68.27, 58.31, $31.91,29.67,29.64,29.62,29.59,29.41,29.35,29.21,26.03,22.68,18.38,14.09$; HRMS (ESI MS) m/z: theor: 708.4986 found: $708.0982([\mathrm{M}+\mathrm{H}]+$ detected).

Synthesis of (2E,2'E)-1,1'-(pyridine-2,6-diyl)bis(3-(2,4-bis(allyloxy)phenyl)prop-2-en1-one) (bis-chalcone 6)

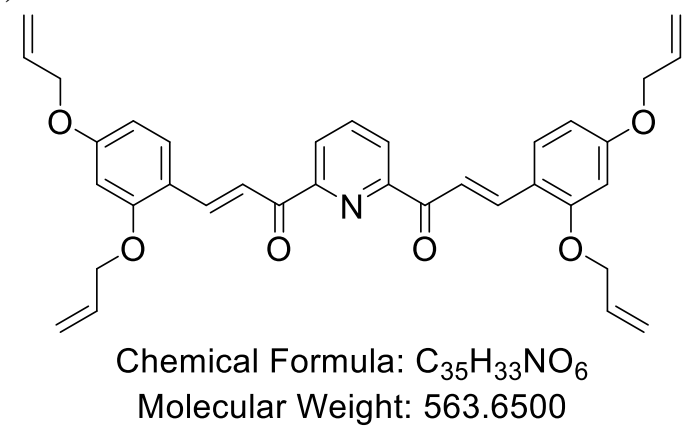

2,4-Bis(allyloxy)benzaldehyde (4.36 g, $20 \mathrm{mmol}, \mathrm{M}=218.25 \mathrm{~g} / \mathrm{mol})$ and 2,6diacetylpyridine ( $1.63 \mathrm{~g}, 10 \mathrm{mmol}, \mathrm{M}=163.18 \mathrm{~g} / \mathrm{mol}$ ) were dissolved in ethanol (50 $\mathrm{mL})$ and aq. $\mathrm{KOH}(40 \%)(15 \mathrm{~mL})$ was added. The solution was stirred at room temperature overnight. During reaction, a precipitate formed. It was filtered off, washed several times with ethanol and dried under vacuum. The resulting solid was dissolved in dichloromethane and the solution was filtered on a plug of $\mathrm{SiO} 2$ using dichloromethane as the eluent. The solvent was removed under reduced pressure. Dissolution in a minimum of dichloromethane followed by addition of pentane precipitated a solid that was filtered off, washed several times with pentane and dried 
under vacuum (3.27 g, 58\% yield). $1 \mathrm{H} \mathrm{NMR} \mathrm{(400} \mathrm{MHz,} \mathrm{CDCl3)} \delta 8.36-8.31(\mathrm{~m}, 6 \mathrm{H})$, $8.02(\mathrm{t}, \mathrm{J}=7.8 \mathrm{~Hz}, 1 \mathrm{H}), 7.70(\mathrm{~d}, \mathrm{~J}=8.6 \mathrm{~Hz}, 2 \mathrm{H}), 6.54(\mathrm{dd}, \mathrm{J}=8.6,2.3 \mathrm{~Hz}, 2 \mathrm{H}), 6.50$ $(\mathrm{d}, \mathrm{J}=2.3 \mathrm{~Hz}, 2 \mathrm{H}), 6.04(\mathrm{ddq}, \mathrm{J}=15.8,11.5,5.2 \mathrm{~Hz}, 4 \mathrm{H}), 5.47-5.35(\mathrm{~m}, 4 \mathrm{H}), 5.33$ $(\mathrm{dd}, \mathrm{J}=10.5,1.3 \mathrm{~Hz}, 2 \mathrm{H}), 5.23(\mathrm{dd}, \mathrm{J}=10.6,1.3 \mathrm{~Hz}, 2 \mathrm{H}), 4.57$ (m, 8H). 13C NMR (101 MHz, $\mathrm{CDCl} 3) \delta 189.30,162.10,159.56,153.79,140.39,137.99,132.72,132.53$, 130.52, 125.41, 119.25, 118.16, 117.99, 117.92, 106.74, 100.22, 69.37, 69.02; HRMS (ESI MS) m/z: theor: 564.2381 found: $564.2380([\mathrm{M}+\mathrm{H}]+$ detected).

Synthesis of (2E,2'E)-1,1'-(pyridine-2,6-diyl)bis(3-(4-(diethylamino)-2(dodecyloxy)phenyl)prop-2-en-1-one) (bis-chalcone 7)

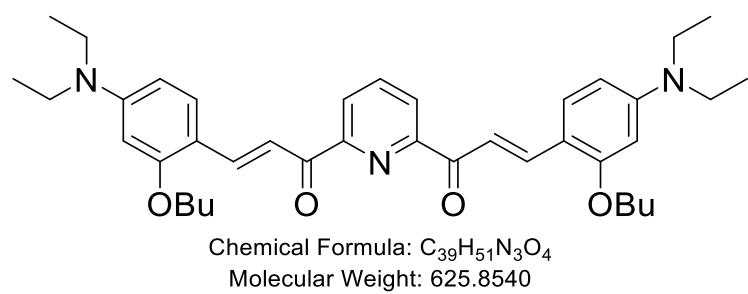

4-(Diethylamino)-2-(butoxy)benzaldehyde (4.99 g, $20 \mathrm{mmol}, \mathrm{M}=249.35 \mathrm{~g} / \mathrm{mol}$ ) and 2,6-diacetylpyridine ( $1.63 \mathrm{~g}, 10 \mathrm{mmol}, \mathrm{M}=163.18 \mathrm{~g} / \mathrm{mol})$ were dissolved in ethanol $(50 \mathrm{~mL})$ and aq. $\mathrm{KOH}(40 \%)(15 \mathrm{~mL})$ was added. The solution was stirred at room temperature overnight. During reaction, a precipitate formed. It was filtered off, washed several times with ethanol and dried under vacuum. The resulting solid was dissolved in dichloromethane and the solution was filtered on a plug of $\mathrm{SiO} 2$ using dichloromethane as the eluent. The solvent was removed under reduced pressure. Dissolution in a minimum of dichloromethane followed by addition of pentane precipitated a solid that was filtered off, washed several times with pentane and dried under vacuum $(5.19 \mathrm{~g}, 83 \%$ yield). $1 \mathrm{H}$ NMR $(400 \mathrm{MHz}, \mathrm{CDCl} 3) \delta 8.38-8.25(\mathrm{~m}, 6 \mathrm{H})$, $7.98(\mathrm{t}, \mathrm{J}=7.7 \mathrm{~Hz}, 1 \mathrm{H}), 7.65(\mathrm{~d}, \mathrm{~J}=8.9 \mathrm{~Hz}, 2 \mathrm{H}), 6.29(\mathrm{dd}, \mathrm{J}=8.8,2.3 \mathrm{~Hz}, 2 \mathrm{H}), 6.12$ $(\mathrm{d}, \mathrm{J}=2.3 \mathrm{~Hz}, 2 \mathrm{H}), 3.99$ (t, J = 6.5 Hz, 4H), $3.41(\mathrm{q}, \mathrm{J}=7.1 \mathrm{~Hz}, 8 \mathrm{H}), 1.82$ (dt, J = 14.3, $6.5 \mathrm{~Hz}, 4 \mathrm{H}), 1.45(\mathrm{dq}, \mathrm{J}=14.7,7.4 \mathrm{~Hz}, 4 \mathrm{H}), 1.21(\mathrm{td}, \mathrm{J}=7.0,3.0 \mathrm{~Hz}, 12 \mathrm{H}), 0.89(\mathrm{t}, \mathrm{J}=$ $7.4 \mathrm{~Hz}, 6 \mathrm{H}) .13 \mathrm{C}$ NMR $(101 \mathrm{MHz}, \mathrm{CDCl} 3) \delta 189.34,160.98,154.47,151.29,141.50$, 137.61, 131.32, 124.77, 115.77, 112.63, 104.44, 94.71, 68.10, 44.66, 31.18, 19.34, 13.78, 12.75; HRMS (ESI MS) m/z: theor: 626.3952 found: $626.3958([\mathrm{M}+\mathrm{H}]+$ detected).

Synthesis of 2,6-bis(3- ferrocenyl- 1 -oxoprop-2-enyl)pyridine (bis-chalcone 8)

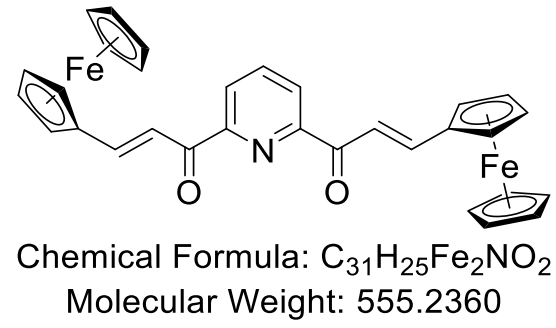


Ferrocenecarboxyaldehyde (3.94 g, $18.39 \mathrm{mmol}, \mathrm{M}=214.04 \mathrm{~g} / \mathrm{mol}))$ and tetrahydro4H-thiopyran-4-one ( $1.5 \mathrm{~g}, 9.19 \mathrm{mmol}, \mathrm{M}=163.17 \mathrm{~g} / \mathrm{mol})$ were dissolved in ethanol $(50 \mathrm{~mL})$ and aq. $\mathrm{KOH}(40 \%)(15 \mathrm{~mL})$ was added. The solution was stirred at room temperature overnight. During reaction, a precipitate formed. It was filtered off, washed several times with ethanol and dried under vacuum. The resulting solid was dissolved in dichloromethane and the solution was filtered on a plug of $\mathrm{SiO} 2$ using dichloromethane as the eluent. The solvent was removed under reduced pressure. Dissolution in a minimum of dichloromethane followed by addition of pentane precipitated a solid that was filtered off, washed several times with pentane and dried under vacuum (3.2 g, 65\% yield). 1H NMR (300 MHz, CDCl3) $\delta 8.35$ (d, J = 7.7 Hz, $2 \mathrm{H}), 8.04(\mathrm{~s}, \mathrm{~J}=7.5 \mathrm{~Hz}, 5 \mathrm{H}), 4.75-4.70(\mathrm{~m}, 4 \mathrm{H}), 4.59-4.53(\mathrm{~m}, 4 \mathrm{H}), 4.22(\mathrm{~s}, 10 \mathrm{H})$; 13C NMR (101 MHz, CDCl3) $\delta 188.0,153.8,147.4,138.3,125.6,118.1,79.7,71.8$, 70.1, 69.4; HRMS (ESI MS) m/z: theor: 556.0657 found: $556.0558([\mathrm{M}+\mathrm{H}]+$ detected).

Synthesis of (2E,2'E)-1,1'-(pyridine-2,6-diyl)bis(3-(2,4-dibutoxyphenyl)prop-2-en-1one) (bis-chalcone 9)

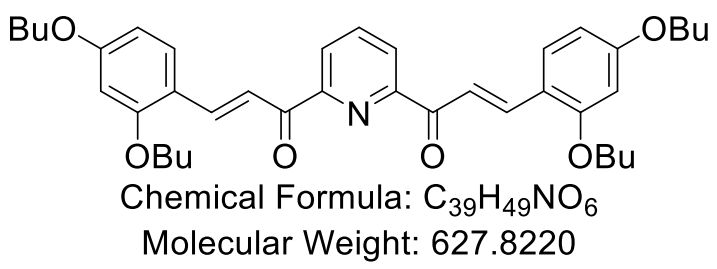

2,4-Butoxybenzaldehyde (5.00 g, $20 \mathrm{mmol}, \quad \mathrm{M}=250.34 \mathrm{~g} / \mathrm{mol})$ and 2,6diacetylpyridine ( $1.63 \mathrm{~g}, 10 \mathrm{mmol}, \mathrm{M}=163.18 \mathrm{~g} / \mathrm{mol}$ ) were dissolved in ethanol (50 $\mathrm{mL})$ and aq. $\mathrm{KOH}(40 \%)(15 \mathrm{~mL})$ was added. The solution was stirred at room temperature overnight. During reaction, a precipitate formed. It was filtered off, washed several times with ethanol and dried under vacuum. The resulting solid was dissolved in dichloromethane and the solution was filtered on a plug of $\mathrm{SiO} 2$ using dichloromethane as the eluent. The solvent was removed under reduced pressure. Dissolution in a minimum of dichloromethane followed by addition of pentane precipitated a solid that was filtered off, washed several times with pentane and dried under vacuum (5.40 g, 86\% yield). $1 \mathrm{H}$ NMR $(400 \mathrm{MHz}, \mathrm{CDCl} 3) \delta 8.38(\mathrm{~d}, \mathrm{~J}=16.1 \mathrm{~Hz}$, $2 \mathrm{H}), 8.32(\mathrm{~d}, \mathrm{~J}=8.9 \mathrm{~Hz}, 2 \mathrm{H}), 8.29(\mathrm{~d}, \mathrm{~J}=17.4 \mathrm{~Hz}, 2 \mathrm{H}), 8.04-7.99(\mathrm{~m}, 1 \mathrm{H}), 7.67(\mathrm{~d}, \mathrm{~J}$ $=8.6 \mathrm{~Hz}, 2 \mathrm{H}), 6.51(\mathrm{dd}, \mathrm{J}=8.6,2.3 \mathrm{~Hz}, 2 \mathrm{H}), 6.46(\mathrm{~d}, \mathrm{~J}=2.3 \mathrm{~Hz}, 2 \mathrm{H}), 3.99(\mathrm{dt}, \mathrm{J}=18.6$, $6.6 \mathrm{~Hz}, 8 \mathrm{H}), 1.85-1.73(\mathrm{~m}, 8 \mathrm{H}), 1.58-1.46(\mathrm{~m}, 4 \mathrm{H}), 1.46-1.35(\mathrm{~m}, 4 \mathrm{H}), 1.00(\mathrm{t}, \mathrm{J}=$ $7.4 \mathrm{~Hz}, 6 \mathrm{H}), 0.87$ (t, J = 7.4 Hz, 6H). 13C NMR (75 MHz, CDCl3) $\delta 189.61,162.95$, 160.48, 154.04, 141.04, 138.06, 131.23, 125.43, 119.20, 117.54, 106.16, 99.60, 68.55, 68.07, 31.39, 31.14, 19.37, 13.97, 13.84; HRMS (ESI MS) m/z: theor: 628.3633 found: $628.3633([\mathrm{M}+\mathrm{H}]+$ detected $)$. 
Synthesis of (2E,2'E)-1,1'-([1,1'-biphenyl]-4,4'-diyl)bis(3-(thiophen-2-yl)prop-2-en-1one) (bis-chalcone 10)

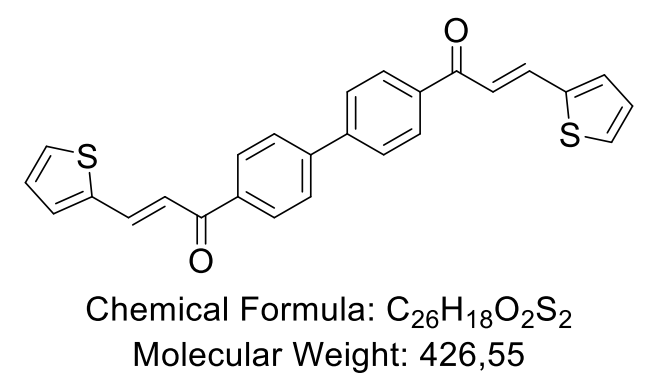

4,4'-Diacetylbiphenyl $(2,38 \mathrm{~g}, \quad 10 \mathrm{mmol}, \quad \mathrm{M}=238.28 \mathrm{~g} / \mathrm{mol})$ and 2thiophenecarboxaldehyde $(2.24 \mathrm{~g}, 20 \mathrm{mmol}, \mathrm{M}=112.15 \mathrm{~g} / \mathrm{mol})$ were dissolved in ethanol $(50 \mathrm{~mL})$ and aq. $\mathrm{KOH}(40 \%)(15 \mathrm{~mL})$ was added. The solution was stirred at room temperature overnight. During reaction, a precipitate formed. It was filtered off, washed several times with ethanol and dried under vacuum. The resulting solid was dissolved in dichloromethane and the solution was filtered on a plug of $\mathrm{SiO} 2$ using dichloromethane as the eluent. The solvent was removed under reduced pressure. Dissolution in a minimum of dichloromethane followed by addition of pentane precipitated a solid that was filtered off, washed several times with pentane and dried under vacuum (2.85 g, 67\% yield). $1 \mathrm{H} \mathrm{NMR}(300 \mathrm{MHz}, \mathrm{CDCl} 3) \delta 8.02-7.95(\mathrm{~m}, 4 \mathrm{H})$, $7.95-7.90(\mathrm{~m}, 2 \mathrm{H}), 7.89-7.81(\mathrm{~m}, 2 \mathrm{H}), 7.67-7.58(\mathrm{~m}, 4 \mathrm{H}), 7.31(\mathrm{~d}, \mathrm{~J}=5.1 \mathrm{~Hz}, 2 \mathrm{H})$, $7.23(\mathrm{dt}, \mathrm{J}=16.7,3.7 \mathrm{~Hz}, 2 \mathrm{H}), 6.97(\mathrm{dt}, \mathrm{J}=7.2,3.6 \mathrm{~Hz}, 2 \mathrm{H})$; 13C NMR (75 MHz, CDCl3) $\delta 189.18,144.13,140.39,137.43,132.23,129.13,129.03,128.43,127.50$, 120.63, 120.60; HRMS (ESI MS) m/z: theor: 427.0821 found: $427.0825([\mathrm{M}+\mathrm{H}]+$ detected). 